\title{
MPP2 Interacts With SK2 Rescue The Excitability of Glutamatergic Neurons in The BLA and Facilitate The Extinction of Conditioned Fear in Mice
}

\section{Xiao-Han Peng}

Xuzhou Medical University https://orcid.org/0000-0002-7994-894X

\section{Pan-Pan Chen}

Xuzhou Medical University

\section{Yang Zhang}

Xuzhou Medical University

\section{$\mathrm{Ke} \mathrm{Wu}$}

Xuzhou Medical University

Ningning Ji

Xuzhou Medical University

Jing-hua Gao

Xuzhou Medical University

Yong-mei Zhang

Xuzhou Medical University

Tie Xu

Xuzhou Medical University

Rong Hua ( $\boldsymbol{D}$ ilovezq@yeah.net)

Xuzhou Medical University

Hui Wang

Xuzhou Medical University

\section{Research Article}

Keywords: basolateral amygdala, membrane palmitoylated protein 2 (MPP2), protein kinase A (PKA), posttraumatic stress disorder (PTSD), small-conductance calcium-activated potassium channel subtype 2 (SK2 channels)

Posted Date: November 9th, 2021

DOI: https://doi.org/10.21203/rs.3.rs-1036689/v1 
License: (c) (i) This work is licensed under a Creative Commons Attribution 4.0 International License. Read Full License 


\section{Abstract}

Posttraumatic stress disorder (PTSD) and other anxiety disorders stem from dysregulated fear memory in which the basolateral amygdala (BLA) plays an integral role. The excitability of glutamatergic neurons in the BLA correlates with fear memory, and the afterhyperpolarization current $\left(\mathrm{I}_{\mathrm{AHP}}\right)$ mediated by smallconductance calcium-activated potassium channel subtype 2 (SK2) dominates the excitability of glutamatergic neurons. However, definitive evidence for the involvement of the SK2 channel in the BLA in fear extinction is lacking. Here, we discovered that fear conditioning decreased the levers of synaptic SK2 channels in the BLA, which were restored following fear extinction. Notably, reduced expression of synaptic SK2 channels in the BLA during fear conditioning was caused by the increased activity of protein kinase A (PKA), while increased levers of synaptic SK2 channels in the BLA during fear extinction were mediated by interactions with membrane palmitoylated protein 2 (MPP2). Collectively, our results revealed that MPP2 interacts with the SK2 channels and rescues the excitability of glutamatergic neurons by increasing the expression of synaptic SK2 channels in the BLA to promote the normalization of fear memory. These findings expand our understanding of the neurobiological mechanism of PTSD and provide a new direction for PTSD treatment.

\section{Introduction}

PTSD (posttraumatic stress disorder), also known as delayed psychogenic reaction, is a chronic and disabling mental illness characterized by intense fear and re-experiencing of fear memory associated with traumatic events. Maladaptive fear extinction is particularly important in the pathogeny of intense fear and re-experiencing fear memory $[1,2]$. The prevalence of PTSD increases with the increase in traumatic events such as natural disasters, traffic accidents, wars, and social and extreme terrorist violence. PTSD is one of the most common psychiatric, illnesses, and the lifetime prevalence rate is $6.8 \%$ in men in the US, according to the Diagnostic and Statistical Manual of Mental Disorders Fifth Edition. PTSD affects the physical and psychological health of patients and exerts negative effects on families and society. The intense fear and re-experiencing of fear memory are key factors influencing the quality of life of patients. At present, the neurobiological mechanism of PTSD is unclear, and no effective clinical practice has been developed for the treatment of PTSD. Therefore, exploring the mechanism of fear extinction not only has important theoretical significance for the neurobiological mechanism of PTSD but also provides a theoretical basis and effective therapeutic targets for treating PTSD.

In rodents, PTSD and general anxiety disorders can be modelled with Pavlovian fear conditioning, a learning task in which an initially neutral conditional stimulus (CS), such as a tone or context, is paired with a naturally aversive unconditional stimulus (US), usually a foot shock [3-5]. In recent years, fear conditioning and extinction have been widely used to assess fear memory, in which foot shock is considered a kind of traumatic stress to acquire fear. We used these paradigms to investigate the mechanism of fear extinction following PTSD. 
The volume of the amygdala is decreased in patients with PTSD, indicating that the structure and function of neurons in the amygdala have changed to result in intense fear and re-experiencing fear memory [6-13]. The amygdala is an almond-shaped cluster of nuclei located deeply and medially within the temporal lobes of the brain in complex vertebrates. The amygdala has two main subregions: the basolateral amygdala complex (BLA), which is divided into the lateral amygdala ( $L A)$ and basal amygdala (BA), and the central amygdala (CeA), which consists of the central lateral (CeL) and central medial (CeM) nuclei [14-16]. A large number of studies suggest an important role for the BLA in the modulation of fear memory, and alterations in BLA neuron excitability are closely associated with the conditioning and extinction of fear memory [17-20]. The BLA consists of glutamatergic neurons and a small number of GABAergic neurons. The principal neurons of the BLA are glutamatergic pyramidal output neurons ( $80-90 \%)$, and their excitability is related to fear conditioning and extinction [21-23]. The SK2 channel regulates the neuronal membrane potential and excitability, suggesting that the abnormal expression, structure and function of the SK2 ion channel may be an important mechanism regulating event-related fear memory.

SK channels are a group of potassium channels with a conductivity value of only 10-20 ps. Their activation is independent of voltage but sensitive to calcium ions. Three SK channel subtypes (SK1-SK3) are expressed throughout the mammalian brain [24]. In the rodent brain, SK1 and SK2 channels are generally co-expressed while SK3 channels are complementarily distributed [25, 26].

Immunohistochemical results showed that the SK2 channel protein was mainly expressed in the BLA, but SK1 and SK3 were almost undetectable [27]. The SK2 channel is related to the regulation of learning and memory, especially fear memory. Some studies have shown that the SK2 channel inhibitor apamin improves spatial memory and contextual fear memory, and SK2 channel agonists weaken the learning and memory of mice [28-30]. SK2 channels are widely expressed in the amygdala, neocortex, hippocampus and thalamus, and an ultrastructural analysis showed that SK2 channels localize to the postsynaptic density (PSD) of neuronal dendritic spines [31]. The SK2 channel specifically mediates mAHP, which reduces the excitability of neurons through a decrease in the firing rate [32,33].

The specific location of the SK2 channel along the neuronal surface is associated with the regulation of mAHP; in addition, mAHP is almost completely produced by postsynaptic mechanisms [34, 35]. Cytoplasmic protein kinase $A(P K A)$ regulates cell signalling and the function of neurons by phosphorylating ion channels. The subcellular distribution and function of SK2 channel is affected by direct PKA-mediated phosphorylation. PKA-mediated phosphorylation of three serine residues (Ser568 570) in the C-terminal domain of the SK2 channel leads to endocytosis of the synaptic SK2 channel [36, 37]. PKA attenuates mAHP, which is specifically mediated by the SK2 channel, by reducing the expression of the SK2 channel at synapses.

Membrane-associated guanylate kinases (MAGUKs) are categorized as scaffold proteins that have many roles in regulating synaptic function and structure and the location and function of synaptic receptors. Membrane palmitoylated protein 2 (MPP2/p55) is a member of the MAGUK family. It contains one PDZ (PSD-95, DLG, ZO-1) domain that is shared by all MAGUKs, one Src homology 3 (SH3) domain, a 
catalytically inactive guanylate kinase (GK) domain and two L27 domains. A recent study indicated that MPP2 and SK2 channels are highly coexpressed in the postsynaptic density of dendritic spines on hippocampal CA1 pyramidal neurons. A complex of the SK2 channel (N-terminal) and MPP2 (SH3-GK domain) in the brains of mice was identified. The SK2 channel contribution to synaptic responses was abolished by downregulating MPP2 expression. In addition, knock down of MPP2 expression decreased LTP [38].

Here, we used paired CS-US and CS alone (unpaired US) to establish the models of conditioned fear memory conditioning and extinction. We hypothesized that PKA phosphorylates the SK2 channel, resulting in endocytosis of the SK2 channel and a decrease in its expression at synaptic, which promotes the fear response. During fear extinction, the expression and function of synaptic MPP2 increase, resulting in an increase the number of postsynaptic SK2 channels, which inhibit the fear response. By studying the expression, distribution and molecular mechanism of the SK2 channel in the process of fear memory, the results will clarify that the modulation of the SK2 channel is an important neurobiological mechanism for fear memory in individual with PTSD and provide a target for clinical translation.

\section{Materials And Methods}

\subsection{Animal care}

Adult male C57BL/6J mice (8 weeks) were purchased from Jinan Pengyue Laboratory Animal Breeding Co. Ltd (Jinan, Shandong, China). Mice had ad libitum access to food and water. The room temperature was $23 \pm 1^{\circ} \mathrm{C}$, and the light/dark environment was $12 \mathrm{~h} / 12 \mathrm{~h}$. All experiments were approved by the Institutional Animal Care and Use Committee of Xuzhou Medical University and fully compliant with the National Institutes of Health Guidelines for the Use and Care of Laboratory Animals. This study was approved by the Xuzhou Medical University experimental animal ethics committee.

\subsection{Delay fear conditioning and extinction}

The conditioned fear box had two different contexts, context A and context B. Context A had black polyester walls and a stainless-steel fence floor. Context B (different backgrounds, smell and light) had white polyester fibre walls and a smooth white polyester fibre floor. Behavioral procedures were performed and improved (foot shock of $1 \mathrm{~mA}$ ) based on previously described methods [39]. All testing was performed using the Near Infrared Fear Conditioning System (Med Associates, St. Albans, VT).

\subsection{Determination of freezing behavior}

After 24 hours of fear conditioning, the mice were tested for their fear response, which was freezing behavior. During freezing behavior, all other movements disappeared except breathing. The mice were placed in context A for 5 min without (any) tone, and the freezing time was observed to test the mouse fear responses as the contextual fear memory test. Before the test, $75 \%$ alcohol was used to clean the test box. Two hours later, the mice were placed in context B to receive CS (30 s) for the observation of 
their freezing behavior, which was used as cued test of fear memory. Before the test, the test box was cleaned with $10 \%$ acetic acid.

\subsection{Immunofluorescence staining}

Male mice were deeply anaesthetized followed by serial intracardial perfusions with $0.9 \%$ saline (100 $\left.\mathrm{mL} \cdot 100 \mathrm{~g}^{-1}\right)$, and $4 \%$ polyformaldehyde in phosphate buffer $\left(100 \mathrm{~mL} \cdot 100 \mathrm{~g}^{-1}\right)$. Whole brains were rapidly dissected and postfixed with $4 \%$ polyformaldehyde at $4^{\circ} \mathrm{C}$ overnight and cryoprotected with $30 \%$ sucrose at $4^{\circ} \mathrm{C}$. Then, the brain tissues were embedded, frozen in OCT at $-20^{\circ} \mathrm{C}$, and sectioned into $30-\mu \mathrm{m}$ slices using a Leica microtome. Brain sections were permeabilized with $0.1 \%$ Triton X-100 in PBS, blocked with $5 \%$ normal bovine serum in PBS, and incubated with primary antibodies at $4^{\circ} \mathrm{C}$ overnight. Subsequently, the brain slices were rinsed three times, incubated with an Alexa Fluor 488-conjugated anti-rabbit or Alexa Fluor 594-conjugated anti-mouse antibody at $\mathrm{r} / \mathrm{t}$ for $2 \mathrm{~h}$, and mounted on positively charged slides. Images were obtained with a confocal laser scanning microscope.

\subsection{Chemogenetic tagging of glutamatergic neurons in the BLA region}

Glutamatergic neurons in the BLA region were labelled with rAVV-CaMKIla-hM4D(Gi)-mCherry-WPRE-pA or rAVV-CaMKIla-mCherry-WPRE-pA. hM4D(Gi) was activated by the selective ligand clozapine-N-oxide (CNO, i.p.), which was dissolved in $2 \%$ DMSO and diluted in sterile saline to a final injection volume of 0.3 $\mathrm{mL} \cdot \mathrm{kg}^{-1}$. Mice undergoing administration of CNO were assessed for fear conditioning or extinction at 60 min after injection.

\subsection{Optogenetic tagging of glutamatergic neurons in the BLA region}

For in vivo optogenetic labelling of glutamatergic neurons in the BLA region, mice underwent a bilateral injection of rAVV-CaMKIla-eNpHR3.0-mCherry-WPRE-hGH-pA or rAVV-CaMKIla-mCherry-WPRE-hGH-pA in the BLA. Three weeks later, for photoinhibition, light trains (589-nm laser, fear conditioning: duration $90 \mathrm{~s}$, interval $60 \mathrm{~s}$; fear extinction: duration of $20 \mathrm{~s}$, interval of $15 \mathrm{~s}$ ) (YL589T6-100FC, Lasercentury, China) were applied to the mice during fear conditioning or extinction. Photostimulation was adjusted by stimulus generator (QAXK-TTL-MC, Thinkertech, China), and the cables were covered with aluminium foil to prevent light leakage.

\subsection{Western blotting Analysis}

The BLA was prepared for western blotting analysis using of Syn-PER Synaptic Protein Extraction Reagent (Thermo Fisher, USA), resulting in both a functional synaptosome fraction and a cytosolic fraction [40]. The protein concentration was determined by using BCA. SDS-PAGE gels were used to separate the same amounts of proteins before transfer to PVDF membranes. The PVDF membrane was blocked with $5 \%$ skim milk or $3 \%$ BSA (bovine serum albumin) at room temperature for 2 hours, and then incubated overnight at $4^{\circ} \mathrm{C}$ with anti-SK2 (1:500; Alomone labs, Israel), anti-PKA (1:1000 Abcam 
ab38949), anti-pPKA (phospho S96, 1:1000 Abcam ab32390), anti-MPP2 (1:1000; Abcam, USA), antiGAPDH (1:1000) or anti- $\beta$ actin(1:3000) primary antibodies. After washes with TBST, the PVDF membrane was incubated with an HRP-conjugated secondary antibody (1:1000) for 45 min at room temperature. Protein bands were illuminated using the BeyoECL Moon kit and captured using the Image ProPlus image analysis system (Media Cybernetics, Inc., Rockville, MD, United States).

\subsection{Electrophysiological Recording}

After injecting rAAV-CaMKIla-mCherry-WPRE-pA (BrainVTA, China) into the BLA, the mice were fed normally for 3 weeks. One hour after fear conditioning or extinction, $10 \%$ chloral hydrate $\left(300 \mathrm{mg} \cdot \mathrm{kg}^{-1}\right)$ was intraperitoneally injected, and $20 \mathrm{ml}$ of precooled high sugar slicing liquid was injected with a $20 \mathrm{ml}$ syringe for perfusion. After perfusion, the brain tissue of the mice was quickly removed, and the whole brain tissue was immersed in the precooled high sugar slicing solution for 2-3 minutes. The brain slices containing the BLA area were incubated in a $34^{\circ} \mathrm{C}$ high sugar solution for $1 \mathrm{~h}$ at room temperature for 30 min and then transferred to the perfusion tank of the electrophysiological operation platform for recording. As our previously published methods, whole-cell recording was used to observe stepped firing rates, electrophysiological patch clamp was performed to record the changes of $\mathrm{I}_{\mathrm{AHP}}$ on glutamatergic neurons in BLA [41]. Cells were held at - $60 \mathrm{mV}$ current-clamp mode, and action potential firings injected

by depolarizing current pulse were recorded by patch-clamp amplifier. In order to record $\mathrm{I}_{\mathrm{AHP}}$ of SK channels, held glutamatergic neurons in voltage-clamp with holding potential of $-60 \mathrm{mV}$ and $100 \mathrm{~ms}$ depolarizing pulse to $60 \mathrm{mV}$ to evoke an outward current. All records were collected using MultiClamp700b, a patch clamp amplifier, and converted with Digidata1440A. The collected signals were recorded and analysed using pCLAMP software.

\subsection{RNA extraction and fluorescence quantitative PCR}

Mice were sacrificed approximately 45 min after fear conditioning or extinction, and total RNA was extracted from the BLA with a Spin Column Animal Total RNA Purification Kit (Sheng-gong, China) according to the manufacturer's instructions. RNA preparations were reverse transcribed to generate cDNAs. The cDNA products were used as templates for real-time PCR analysis to measure SK2 or MPP2 expression using SK2-specific primers (Sheng-gong, China) or MPP2-specific primers (Sheng-gong, China). Sense and antisense primers were selected to be located on different exons to avoid falsepositive results caused by genomic DNA contamination. PCR was performed with a Light Cycler 480 System using fluorescent SYBR Green technology (Applied Biosystems). Reaction protocols had the following format: $1 \mathrm{~min}$ at $95^{\circ} \mathrm{C}$ for enzyme activation followed by 40 cycles of $10 \mathrm{~s}$ at $95^{\circ} \mathrm{C}, 30 \mathrm{~s}$ at $60^{\circ} \mathrm{C}$ and $30 \mathrm{~s}$ at $72^{\circ} \mathrm{C}$. Then, the samples were incubated at $95^{\circ} \mathrm{C}$ for $5 \mathrm{~s}$ and $60^{\circ} \mathrm{C}$ for $60 \mathrm{~s}$. A melting curve analysis was performed to assess the specificity of the amplification products. All reactions contained the same amount of cDNA templates. The relative expression ratio of SK2 mRNA was normalized to GAPDH gene expression using the $\triangle \mathrm{Ct}$ method $\left(2^{-} \Delta \Delta \mathrm{Ct}\right)$. The primer sequences (Sheng-gong, China) were as follows (5'-3', F: forward, R: reverse):

SK2: F: CTGCTTGCTTACTGGAATCATG, R: CATCATGAAATTGTGCACATGC; 


\section{GAPDH: F: AGGCCGGTGCTGAGTATGTC, R: TGCCTGCTTCACCACCTTCT.}

\subsection{Stereotactic Microinjection}

We anaesthetized mouse with $1.5 \%$ isoflurane and implanted a stainless-steel guide (outer tube) into the BLA nucleus (anteroposterior: $3.14 \mathrm{~mm}$; lateral: $-1.46 \mathrm{~mm}$; ventral: $-5 \mathrm{~mm}$ ) at least one week before drugs injection. The injection needle tube (inner tube) was connected to the Hamilton microinjector driven by the/microinfusion pump (KD Scientific) through the polyethylene tube. Microinjection was performed in a $0.5 \mu \mathrm{l}$ volume delivered over $1 \mathrm{~min}$. Anaesthesia was stopped immediately after the microinjection. Before removal, the injection needle was left in the original position for an additional 5-10 minutes to minimize dragging of the injected liquid along the injection tract. After approximately $30 \mathrm{~min}$, the mice were fully awake, and the next experimental operation was carried out.

\subsection{Co-immunoprecipitation}

The BLA was extracted and lysed with IP lysis buffer (Beyotime, China). The lysate was centrifuged at $13,000 \mathrm{rpm}$ for $10 \mathrm{~min}$ at $4^{\circ} \mathrm{C}$. The supernatant was incubated with the indicated anti-SK2 antibody overnight at $4^{\circ} \mathrm{C}$ with rotation. Then, $30 \mu \mathrm{l}$ of Protein $\mathrm{A} / \mathrm{G}$ agarose beads (Thermo Scientific) were added and incubated for $3 \mathrm{~h}$. The beads were washed three times with IP lysis buffer; then, $20 \mu \mathrm{l}$ of $2 \mathrm{X}$ SDS loading buffer were added and boiled for $10 \mathrm{~min}$. Bound and eluted proteins were subsequently separated on SDS-PAGE gels and transferred to PVDF membranes. After blocking with $5 \%$ skim milk or $3 \%$ BSA for $2 \mathrm{~h}$, the membrane was probed with the anti-MPP2 antibody overnight at $4^{\circ} \mathrm{C}$. An HRP-conjugated secondary antibody was applied for $45 \mathrm{~min}$. Blots were detected with BeyoECL Moon kit and developed with an Image ProPlus image analysis system.

\subsection{Drug treatment}

1-EBIO (1-Ethylbenzimidazolinone, $300 \mathrm{ng} 1.85 \mathrm{nmol} 300 \mathrm{nl}$ ) was dissolved in dimethyl sulfoxide (DMSO). Apamin (2.5 pmol, $300 \mathrm{nl}$ ), 8-Br-cAMP (8-Bromoadenosine 3', 5'-cyclic monophosphate, 2.5 pmol, $300 \mathrm{nl}$ ), and Rp-8-Br-cAMP (30 pmol, $300 \mathrm{nl}$ ) were dissolved in saline. siRNA (siRNA targeting MPP2, 5'CCUAGAACAUGGCGAGUAUTT3', 5'-AUACUCGCCAUGUUCUAGGTT-3', 1 ug•ul' ${ }^{-1}, 300 \mathrm{nl}$ ), NC (negative control, sense 5'-UUCUCCGAACGUGUCACGUTT-3' antisense 5'-ACGUGACACGUUCGGAGAATT-3', 1 ug.ul' ${ }^{-1}$, 300nl) was designed and produced by Suzhou Genepharma Co.,Ltd. Controls were administered the vehicle alone.

\subsection{Statistics}

Student $t$ test was used to compare between 2 groups. One-way ANOVA or two-way ANOVA followed by a Tukey multiple comparison test was used to compare among $>2$ groups. $p<0.05$ was considered significant. SPSS19 and GraphPad Prism 7.0 software were used to analyze the data and generate graphs. All data are presented as mean \pm SEM. 


\section{Results}

\subsection{Fear conditioning and extinction in cue-dependent fear conditioning paradigms in mice}

We used fear conditioning and extinction to model the acquisition and extinction of fear memory in PTSD. The fear memory of mice was evaluated by observing their fear responses. The percentage of freezing was used to represent the fear response. On Day 1, the mice received three paired CS-US as fear conditioning in the fear box where the tone $(30 \mathrm{~s}, 90 \mathrm{~dB}, 8000 \mathrm{~Hz})$ served as the CS and foot shock ( $1 \mathrm{~s}, 1$ $\mathrm{mA}$ ) served as the US. On Day 2, mice were returned to the other box (a modified chamber with different colors, context, lighting, and odours) for $20 \mathrm{CSs}$ for fear extinction. Cued and contextual fear memory were tested on the second day of fear acquisition (Fig. 1a, b). From the second CS-US, the percentage of freezing in the FC group was higher than that in the Control group, and as the number of CS-US increased, the percentage of freezing increased significantly (Fig. 1C). Through the contextual fear memory (Fig. 1d) and cued fear memory tests (Fig. 1e) we found that the freezing time of mice in the Fear conditioning group was higher than that of the Control group. When fear extinction occurred, the percentage of freezing decreased with the increase in the number of CSs, and the difference was statistically significant from 11-15 CSs (Fig. 1f). In conclusion, we concluded that CS-US induced fear memory in mice, while repeated exposure to multiple CSs alone induced fear extinction on the second day.

\subsection{Glutamatergic neurons in the BLA are activated during fear conditioning and extinction}

We observed the excitability of glutamatergic neurons in the BLA during fear conditioning and extinction by performing immunofluorescence staining and recording the evoked firing rate. First, we observed the co-expression of c-Fos and CaMKII protein using immunofluorescence dual-labelling. The coexpression of c-Fos and CaMKIla proteins was higher in the Fear extinction group than that in the Control group and lower than that in the Fear conditioning group, indicating that the excitability of glutamatergic neurons was increased through fear conditioning and restored during fear extinction (Fig. 2a, b). The percentage of CaMKII-positive neurons among c-Fos-positive neurons in the BLA was more than $80 \%$, which indicated that most of the neurons activated by fear conditioning and fear extinction were glutamatergic neurons (Fig. 2a, c). mCherry-labelled glutamatergic neurons were observed in the BLA by microinjecting rAVV-CaMK\a-mCherry-WPRE-pA, which contains the CaMKIla promoter (Fig. 2d, e). The evoked firing rate of glutamatergic neurons was observed using the whole-cell patch-clamp technique. With different injection currents, the evoked firing rate of glutamatergic neurons in the BLA of mice in the Fear extinction group was higher than that in the Control group and lower than that in the Fear conditioning group (Fig. 2f).

We transduced BLA glutamatergic neurons with hM4Di fused to mCherry, or with the same viral vector carrying only mCherry using recombinant adeno-associated virus under the control of the CaMKIla promoter to explore the effects of glutamatergic neurons in the BLA on fear memory in mice. CNO (0.3 
$\mathrm{mg} \cdot \mathrm{kg}^{-1}$ ) was intraperitoneally injected to activate the virus $1 \mathrm{~h}$ before fear conditioning or extinction (Fig. 3a). mCherry-positive puncta were immunoreactive for anti-CaMKII (Fig. 3b), consistent with the localization of the virally expressed protein to glutamatergic neurons in the BLA. In fear learning, the percentage of freezing time in hM4Di group was similar to that in the Control group, indicating that chemogentic inhibition of glutamatergic neurons in the BLA did not affect fear acquisition in mice (Fig. 3c). Compared to control subjects, the hM4Di group exhibited a decreased fear response, as indicated by a lower percentage of freezing during contextual and cued fear memory tests and during fear extinction (Fig. 3d-f).

Next, in optogenetic experiments, we microinjected the mouse BLA with viruses expressing either the inhibitory opsin eNpHR3.0 or mCherry control virus under control of the CaMKIla promoter and observed its role in fear memory (Fig. 4a). Confocal analyses of the BLA revealed extensive immunolocalization of mCherry-labelled puncta with CaMKII, consistent with the localization of virus specific protein expression to glutamatergic neurons in the BLA (Fig. 4b). In fear learning, neuronal inhibition induced by eNpHR3.0 had no effect on the percentage of freezing time but decreased the fear response in the contextual and cued fear memory tests and during fear extinction (Fig. 4c-f).

In summary, glutamatergic neurons in the BLA were hyperactivated during fear conditioning and this hyperactivation was rescued by fear extinction. Inhibition of this hyperactivation by chemogentics and optogenetics reduced the fear response in contextual and cued fear memory and during fear extinction in mice.

\subsection{SK2 channels in glutamatergic neurons of the BLA are associated with fear conditioning and extinction}

We first determined the expression of the SK2 channel in BLA glutamatergic neurons by performing immunofluorescence dual-labelling to investigate the relationship between the SK2 channel and glutamatergic neurons. Quantification of the expression of SK2 and CaMKII in BLA neurons showed that more than $80 \%$ of CaMKII-expressing cells colocalized with SK2 ${ }^{+}$neurons, suggesting that most of the neurons expressing SK2 channel are glutamatergic neurons in the BLA (Fig. 5a, b). Then, we explored the expression of total SK2 channels by performing Western blotting and RT-PCR. Fear conditioning and extinction had no effect on the expression of the total SK2 channel (Fig. 5c, d). Next, we extracted synaptosome for Western blotting. The expression of synaptic SK2 channels was decreased in mice subjected to fear conditioning and restored in mice in the Fear extinction group (Fig. 5e). We proceeded to investigate the relationship between the SK2 channel and the excitability of glutamatergic neurons by recording the $\mathrm{I}_{\mathrm{AHP}}$ mediated by the SK2 channel expressed on glutamatergic neurons in the BLA [35]. The decrease in the average peak amplitude of $\mathrm{I}_{\mathrm{AHP}}$ was associated with fear conditioning and that the partial increase in this current was related to fear extinction, suggesting that the hyperactivation of glutamatergic neurons correlates with fear conditioning and that fear extinction rescues this hyperactivation (Fig. 5f). Taken together, in the BLA, decreasing the expression and function of synaptic 
SK2 channels is conducive to fear conditioning, while increasing these parameters promotes fear extinction.

\subsection{Effects of pharmacological regulation of the SK2 channel in the BLA on fear conditioning and extinction}

The SK2 channel activator 1-EBIO (300 ng, $300 \mathrm{nl})$, SK2 channel blocker apamin ( $2.5 \mathrm{pmol}, 300 \mathrm{nl})$ and their respective controls were microinjected into the BLA 30 minutes prior to fear conditioning to regulate the SK2 channel and to further explore its role in fear memory (Fig. 6a). At 24 hours post-injection, mice were subjected to contextual and cued fear memory tests. Neither 1-EBIO-treated mice (Fig. 6b) nor apamin-treated mice (Fig. 6g) showed significant differences in fear learning. In the subsequent fear memory test, compared with the DMSO group, the percentage of freezing decreased in the tested mice (Fig. 6c, d), suggesting that the contextual and cued fear memory of mice in the 1-EBIO group were significantly impaired. In contrast, apamin did not exert a significant effect on contextual (Fig. 6h) or cued fear memory (Fig. 6i).

The mice were randomly divided into 4 groups after fear conditioning to examine the role of the SK2 channel in fear extinction. Then 1-EBIO, apamin, and their respective controls were microinjected into the BLA 30 minutes prior to fear extinction. These mice were then subjected to 20 presentations of sound stimulation (CS) in the fear box (Fig. 6f). Compared with the Control group, the percentage of freezing was lower in mice from the 1-EBIO group, but higher in the apamin group, confirming that 1-EBIO was helpful for fear extinction (Fig. 6e) while apamin prevented fear extinction (Fig. 6j). These data indicate that the SK2 channel in the BLA indeed plays a key role in fear conditioning and extinction.

\subsection{Activated PKA strengthens fear conditioning by phosphorylating synaptic SK2 channels}

We further explored whether phosphorylated PKA was associated with fear memory by regulating the expression of the SK2 channel. First, we found that fear conditioning and extinction had no effect on the cytoplasmic PKA level (Fig. 7b). However, fear conditioning increased the cytoplasmic pPKA level, which was restored by fear extinction (Fig. 7c). The PKA activator 8-Br-cAMP (2.5 pmol, $300 \mathrm{nl}$ ) or inhibitor Rp-8Br-cAMP (30 pmol, $300 \mathrm{nl}$ ) was microinjected into BLA 30 minutes prior to fear conditioning to determine whether activated PKA reduced synaptic SK2 levels by increasing SK2 phosphorylation (Fig. 7a). Next, we obtained BLA tissues 45 min after fear conditioning for Western blotting. Treatment with 8-Br-cAMP reduced the expression of synaptic SK2 channels (Fig. 7i), and Rp-8-Br-cAMP treatment increased the expression of synaptic SK2 channels (Fig. 7j), suggesting that phosphorylated PKA reduced the expression of synaptic SK2 channels during fear conditioning. In fear learning, microinjecting 8-Br-cAMP and Rp-8-Br-cAMP into the BLA had no effects on fear conditioning (Fig. 7d). In the subsequent contextual and cued fear memory tests, PKA inhibition significantly reduced fear memory, while PKA activation had no effects on fear memory (Fig. 7e, f). A potential explanation for this finding is a sufficiently high degree of fear; even if the PKA and synaptic SK2 channels have changed at the 
molecular level, the behavior cannot express greater fear. In summary, phosphorylated PKA correlated with fear conditioning by reducing the expression of synaptic SK2 channels.

We next examined whether the expression of SK2 mediated by activated PKA was involved in fear extinction. Thirty minutes before fear extinction, 8-Br-cAMP, Rp-8-Br-cAMP or their vehicles were microinjected into BLA of the two groups of mice (Fig. 7g). We obtained BLA tissues 45 min after fear extinction for Western blot analysis. The injection of 8-Br-cAMP (Fig. 7k) into the BLA reduced the expression of synaptic SK2 channels, but the injection of Rp-8-Br-cAMP into the BLA did not affect the expression of synaptic SK2 channels (Fig. 7l). PKA activation increased the cytoplastic pPKA level in response to both fear conditioning and fear extinction but only decreased the expression of synaptic SK2 channels in fear conditioning but not in fear extinction. We observed the effect of regulating PKA on fear extinction. The activation or inhibition of PKA did not alter fear extinction (Fig. 7h). Combined with the molecular results, we speculate that increased expression of SK2 channels by activated PKA may play a major role in fear conditioning, while regulation of PKA to change the expression of synaptic SK2 channels does not play a leading role in fear extinction. What factor plays an important role in mediating the expression of synaptic SK2 during fear extinction?

\subsection{MPP2 downregulation in the BLA reduces fear extinction by decreasing the expression of synaptic SK2 channels}

According to previous studies, MPP2 is a synaptic scaffold protein located in postsynaptic density, and the SK2 channel acts by anchoring to the synapse through MPP2 [38, 42]. Therefore, we tested whether synaptic SK2 channels are anchored by the MPP2 scaffold in the BLA. First, in contrast to the mice in the Fear conditioning group, the expression of synaptic MPP2 in the BLA was increased in the Fear extinction group (Fig. 8a). We explored whether the SK2 channel interacted with MPP2 in the BLA by performing coimmunoprecipitation experiments. Western blotting with anti-MPP2 antibody detected a band of the appropriate apparent molecular weight for MPP2 in the BLA sample precipitated with an SK2 antibody, suggesting that the SK2 channel interacts with MPP2 in the BLA (Fig. 8b). Next, we used an siRNA targeting MPP2 (siRNA, Gene Pharma, Suzhou, China) to knock down MPP2 expression in the BLA. The PCR results showed that MPP2-siRNA decreased the expression of the MPP2 mRNA (Fig. 8c). Thirty hours before fear conditioning, the mice were separately injected with MPP2-siRNA or the negative control (NC) in the BLA (Fig. 8d). The percentage of freezing was not significantly difference in fear conditioning between the MPP2-siRNA and Control groups (Fig. 8e). On the next day, we evaluated the contextual and cued fear memory of mice. The results indicated that MPP2 knockdown had no effect on contextual memory (Fig. 8f) or cued memory (Fig. 8g). At 45 minutes after fear conditioning, the BLA was extracted and used for Western blot analysis. The siRNA targeting MPP2 decreased synaptic MPP2 (Fig. 8h) and the expression of synaptic SK2 channel levels (Fig. 8i) in fear conditioning. In conclusion, knockdown of MPP2 during fear conditioning decreased the expression of synaptic SK2 channel, but did not affect fear response. 


\subsection{MPP2 downregulation in the BLA reduced fear extinction by decreasing the expression of synaptic SK2 channels}

Four hours before fear conditioning, mice were separately injected with MPP2-siRNA and negative control siRNA in the BLA to examine the effect of MPP2 on fear extinction through the SK2 channel. On the next day, 40 min before fear extinction, the mice in the MPP2-siRNA group were randomly divided into 3 groups, two of which were injected with 1-EBIO and DMSO into the BLA (Fig. 9a). Compared to control subjects, the siRNA group exhibited increased fear response behaviors, as indicated by a greater number of freezing behaviors during fear extinction, and significant activation of the SK2 channel by 1-EBIO counteracted the increase in the fear response (Fig. 9b). At 45 minutes after fear conditioning or fear extinction, the BLA was extracted and used for Western blot analysis. The siRNA decreased synaptic MPP2 levels in response to fear extinction (Fig. 9c). Microinjection of the siRNA targeting MPP2 into the BLA significantly reduced the expression of synaptic SK2 channels in animals subjected to fear extinction (Fig. 9d). We labelled glutamatergic neurons with the virus rAVV-CaMKIla-mCherry-WPRE-pA to test the effect of MPP2 on glutamatergic neurons through the SK2 channel in the BLA. Then, before observing the evoked firing rate of glutamatergic neurons and the average peak amplitude of $\mathrm{I}_{\mathrm{AHP}}$ through electrophysiology, we injected the siRNA and negative control into the BLA (Fig. 9e). The evoked firing rate of glutamatergic neurons in the siRNA group was higher than that in the Control group (Fig. 9f, g), and the average peak amplitude of $\mathrm{I}_{\mathrm{AHP}}$ of glutamatergic neurons in siRNA group was lower than that in Control group (Fig. 9h). This result suggested that MPP2 knockdown increased the activity of glutamatergic neurons by decreasing the expression and function of synaptic SK2 channels. In conclusion, in the BLA, MPP2 interacts with the SK2 channel, thereby decreasing the activity of glutamatergic neurons to enhance fear extinction, but it does not play a major role in fear conditioning.

\section{Discussion}

In the present study, we provided novel evidence that synaptic SK2 channels in the BLA are involved in the formation and extinction of fear in mice by mediating the excitability of glutamatergic neurons. Specifically, the regulation of synaptic SK2 by PKA participates in the coding of fear memory (CS-US), while MPP2-mediated changes in synaptic SK2 expression and function play a role in the coding of fear memory extinction (CS-No US).

The models of fear conditioning and extinction are often used to explore the mechanism of PTSD. Fear conditioning induced by multiple pairs of CS-US caused mice to acquire associative fear memory. Then, many CS (No US)-mediated fear extinctions caused the mice to form a new associative memory. Generalization of fear memory and fear extinction disorder are the main symptoms and pathogeny of PTSD. Therefore, studies aiming to discover the factors that enhance or impair fear memory and fear extinction is conducive to exploring the pathogenesis of PTSD and providing new targets for the treatment of PTSD. 
The important neural structure involved in PTSD is part of the limbic system, an important region for emotion processing in humans and animals [43]. In individuals with PTSD, the amygdala, hippocampus and prefrontal cortex are the three most obvious areas of the limbic system shoeing altered function. In studies of Pavlovian conditioned fear in animals and humans, the amygdala regulates fear memory and receives neural projections from the hippocampus and prefrontal cortex [44-46]. In present study, the excitability of glutamatergic neurons in the BLA was significantly increased during fear conditioning and extinction, while the excitability of glutamatergic neurons in the BLA was lower during fear extinction. Based on these results, glutamatergic neurons in the BLA are hyperactivated during fear conditioning and must be excited to produce associative memory $[17,18]$. The explanation for the lower excitability of fear extinction may be due to the inhibitory effect of the new associative memory on fear memory or the low activation of neurons required for the generation of a new associative memory. Inhibiting the excitability of glutamatergic neurons in BLA using chemogenetics and optogenetics weakened cued and contextual fear memory, consistent with the results reported by Sengupta [47]. Inhibiting the excitability of BLA glutamatergic neurons during fear extinction may cause changes in the excitatory/inhibitory (E/I) balance in the MPFC-BLA pathway, which is beneficial to fear extinction by inhibiting the hyperexcitability of glutamate neurons induced by fear conditioning [48].

As a key regulator of amygdala neuronal excitability, we speculated that synaptic SK2 channels participate in the regulation of glutamatergic neuronal excitability in the BLA by mediating mAHP. SK channels are located in the postsynaptic membrane of glutamatergic neurons in close proximity to $\mathrm{N}$ methyl-D-aspartate receptors (NMDARs), where they are activated by NMDAR-mediated $\mathrm{Ca}^{2+}$ influx. Opening of SK channel induces $\mathrm{K}^{+}$efflux which alters the membrane potential [49]. Furthermore, $\mathrm{K}^{+}$efflux and SK channel-mediated reduction of $\left[\mathrm{Ca}^{2+}\right]$ create a local current that re-establishes NMDA receptor blockade by $\mathrm{Mg}^{2+}$, thereby preventing re-excitation of the neurons [50]. The SK2 channel might modulate the excitability of neurons in the BLA through affecting NMDARs. In addition, recent studies have examined the role of SK channels in serotonergic neurons in model systems of mood disorders such as depression [51]. Further studies are needed to explore how SK2 channels regulate the excitability of neurons in the BLA.

We also explored the mechanisms underlying the roles of synaptic SK2 channels in fear conditioning and extinction. The cytoplasmic PPKA level in the BLA was increased in response to fear conditioning and restored by fear extinction. Then, we perceived that the regulation of PKA was important to the expression of synaptic SK2. Indeed, in fear conditioning PKA activation significantly reduced the synaptic SK2 channel abundance, while PKA inhibition significantly increased the synaptic SK2 channel abundance and fear memory. Therefore, we speculated that PKA activation was involved in the decrease in synaptic SK2 channels in the BLA through phosphorylation and the process of synaptic SK2 channel endocytosis in fear conditioning. As the fear response seems to have reached its peak, further activation of PKA did not significantly increase the fear response. In the BLA, activation of the cAMP-PKA pathway is involved in memory consolidation [52, 53]. Therefore, PKA agonists may activate other pathways (cAMP-PKA) while promoting the depression of SK2 channel. Thus, the mechanism by which SK2 mediates fear 
conditioning is a decrease in the expression of synaptic SK2 induced by cytoplasmic PKA-mediated phosphorylation. However, the mechanism did not have an important function in fear extinction.

Furthermore, we identified a major role for MPP2 in regulating the expression of synaptic SK2 channels during fear extinction. In the BLA, the SK2 channel interacts with MPP2. Knockdown of MPP2 decreased the expression of synaptic SK2 in the BLA and reduced fear extinction. However, MPP2 knockdown did not significantly affect fear memory during fear conditioning. Numerous studies have highlighted that acute disruptions of synaptic MAGUKs dramatically affect NMDA receptor- or AMPA receptor-mediated currents and long-term potentiation [54-58]. Therefore, we cannot exclude the possibility that reducing MPP2 levels directly or indirectly affects fear memory through its interactions with other channels. The shared domain of MAGUK proteins is the PDZ domain, which plays an important role in promoting the aggregation and function of various ion channels (such as $\mathrm{Ca}^{2+}$ channels and $\mathrm{K}^{+}$channels) $[59,60]$. In CA1 hippocampal neurons, the SH3-HOOK-GK domain of MPP2 interacts with the N-terminal domain of SK2 [38]. MAGUKs also contain phosphorylation sites, which can be used as auxiliary peptides to regulate the function and format of gated ion channels by interacting with ion channels[61, 62]. The domain of MPP2 that interacts with the SK2 channel in the BLA and the mechanism by which MPP2 mediates the expression of the SK2 channel must be explored.

\section{Conclusion}

In conclusion, synaptic SK2 channels in the BLA correlate with the regulation of fear conditioning and extinction by modulating the activity of glutamatergic neurons. In fear conditioning, the excitability of glutamatergic neurons is increased, which may be relevant to activated PKA phosphorylating synaptic SK2 channels, by which it promotes the endocytosis of the synaptic SK2 channel and reduces its expression in the synapse (Fig. 10c, d). Conversely, the decrease in the excitability of glutamatergic neurons might be related to an increase in SK2 channels in synapse by anchoring the SK2 channel to the synapse through MPP2 during fear extinction (Fig. 10d, e). These findings validated that the conditioning and extinction of fear memory are not reversible processes. The mechanism by which MPP2 interacts with SK2 remains to be clarified. Furthermore, studies designed to explore whether MPP2 affects fear memory through other pathways will be important.

\section{Declarations}

Availability of Data and Material All data of the study can be acquired from corresponding author through email.

Authors' Contributions RH, TX, YMZ, PPC, XHP and YZ participated in the research design. XHP, PPC, YZ, $\mathrm{KW}, \mathrm{NNJ}, \mathrm{JHG}$ and $\mathrm{HW}$ performed the experiments and data analysis; $\mathrm{RH}, \mathrm{YMZ}, \mathrm{XHP}$, and $\mathrm{YZ}$ contributed to the preparation of the paper. 
Funding This work was supported by grants from the National Natural Science Foundation of China [81772065, 81771203, 82071228], Key Subject of Colleges and Universities Natural Science Foundation of Jiangsu Province [19KJA 110001].

Animal Experiments All experiments were approved by the Institutional Animal Care and Use Committee of Xuzhou Medical University and fully compliant with the National Institutes of Health Guidelines for the Use and Care of Laboratory Animals. This study was approved by the Xuzhou Medical University experimental animal ethics committee.All efforts were made to minimize animal suffering, reduce the number of animals used, and utilize alternatives to in vivo techniques, when available.

Acknowledgements Not applicable.

Consent to Participate Not applicable.

Consent to Publish Not applicable.

Data Availability The datasets that support the findings of this study are available from the corresponding author upon reasonable request.

Code Availability Not applicable.

\section{Compliance with Ethical Standards}

Conflict of Interests All authors declare that they have no conflicts of interest.

\section{References}

1. Wicking M, Steiger F, Nees F, Diener SJ, Grimm O, Ruttorf M et al (2016) Deficient fear extinction memory in posttraumatic stress disorder. Neurobiol Learn Mem 136:116-126. https://doi.org/10.1016/j.nlm.2016.09.016

2. Baek J, Lee S, Cho T, Kim SW, Kim M, Yoon Y et al (2019) Neural circuits underlying a psychotherapeutic regimen for fear disorders. Nature 566:339-343. https://doi.org/10.1038/s41586019-0931-y

3. Mahan AL, Ressler KJ (2012) Fear conditioning, synaptic plasticity and the amygdala: implications for posttraumatic stress disorder. Trends Neurosci 35:24-35. https://doi.org/10.1016/j.tins.2011.06.007

4. Kida S (2019) Reconsolidation/destabilization, extinction and forgetting of fear memory as therapeutic targets for PTSD. Psychopharmacology 236:49-57. https://doi.org/10.1007/s00213018-5086-2

5. Phillips, RG,LeDoux JE (1992) Differential contribution of amygdala and hippocampus to cued and contextual fear conditioning. Behav Neurosci 106:274-285. https://doi.org/10.1037//07357044.106.2.274 
6. Liberzon I, Taylor SF, Amdur R, Jung TD, Chamberlain KR, Minoshima S et al (1999) Brain activation in PTSD in response to trauma-related stimuli. Biol Psychiatry 45:817-826.

https://doi.org/10.1016/s0006-3223(98)00246-7

7. Rauch SL, Shin LM, Wright Cl (2003) Neuroimaging studies of amygdala function in anxiety disorders. Ann N Y Acad Sci. https://doi.org/10.1111/j.1749-6632.2003.tb07096.X. .985:389-410

8. Rauch SL, van der Kolk BA, Fisler RE, Alpert NM, Orr SP, Savage CR et al (1996) A symptom provocation study of posttraumatic stress disorder using positron emission tomography and scriptdriven imagery. Arch Gen Psychiatry 53:380-387. https://doi.org/10.1001/archpsyc.1996.01830050014003

9. Rauch SL, Whalen PJ, Shin LM, Mclnerney SC, Macklin ML, Lasko NB et al (2000) Exaggerated amygdala response to masked facial stimuli in posttraumatic stress disorder: a functional MRI study. Biol Psychiatry 47:769-776. https://doi.org/10.1016/s0006-3223(00)00828-3

10. Shin LM, Kosslyn SM, McNally RJ, Alpert NM, Thompson WL, Rauch SL et al (1997) Visual imagery and perception in posttraumatic stress disorder. A positron emission tomographic investigation. Arch Gen Psychiatry 54:233-241. https://doi.org/10.1001/archpsyc.1997.01830150057010

11. Neves LT, Neves PFR, Paz LV, Zancan M, Milanesi BB, Lazzari GZ et al (2019) Increases in dendritic spine density in BLA without metabolic changes in a rodent model of PTSD. Brain Structure and Function 224:2857-2870. https://doi.org/10.1007/s00429-019-01943-4

12. Radulovic J, Ren LY, Gao C (2019) N-Methyl D-aspartate receptor subunit signaling in fear extinction. Psychopharmacology 236:239-250. https://doi.org/10.1007/s00213-018-5022-5

13. Regev-Tsur S, Demiray YE, Tripathi K, Stork O, Richter-Levin G, Albrecht A (2020) Region-specific involvement of interneuron subpopulations in trauma-related pathology and resilience. Neurobiol Dis 143:104974. https://doi.org/10.1016/j.nbd.2020.104974

14. Squire LR (2009) Encyclopedia of neuroscience. ed. Elsevier/Academic Press: Amsterdam; Boston; 2009.

15. Paxinos G (2015) The rat nervous system. Fourth edition. ed. Elsevier/AP, Academic Press is an imprint of Elsevier: Amsterdam;

16. Lingawi NW, Laurent V, Westbrook RF, Holmes NM (2019) The role of the basolateral amygdala and infralimbic cortex in (re)learning extinction. Psychopharmacology 236:303-312. https://doi.org/10.1007/s00213-018-4957-x

17. Sehgal M, Ehlers VL, Moyer JR Jr (2014) Learning enhances intrinsic excitability in a subset of lateral amygdala neurons. Learn Mem 21:161-170. https://doi.org/10.1101/lm.032730.113

18. Lin HC, Mao SC, Su CL, Gean PW (2010) Alterations of excitatory transmission in the lateral amygdala during expression and extinction of fear memory. Int J Neuropsychopharmacol 13:335345. https://doi.org/10.1017/S1461145709990678

19. Karst H, Joels M (2016) Severe stress hormone conditions cause an extended window of excitability in the mouse basolateral amygdala. Neuropharmacology 110:175-180.

https://doi.org/10.1016/j.neuropharm.2016.07.027 
20. Zhang WH, Liu WZ, He Y, You WJ, Zhang JY, Xu H et al (2019) Chronic Stress Causes ProjectionSpecific Adaptation of Amygdala Neurons via Small-Conductance Calcium-Activated Potassium Channel Downregulation. Biol Psychiatry 85:812-828.

https://doi.org/10.1016/j.biopsych.2018.12.010

21. Sengupta A, Winters B, Bagley EE, McNally GP (2016) Disrupted Prediction Error Links Excessive Amygdala Activation to Excessive Fear. J Neurosci 36:385-395. https://doi.org/10.1523/JNEUROSCI.3670-15.2016

22. Bloodgood DW, Sugam JA, Holmes A, Kash TL (2018) Fear extinction requires infralimbic cortex projections to the basolateral amygdala. Transl Psychiatry 8:60. https://doi.org/10.1038/s41398018-0106-x

23. Molosh Al, Dustrude ET, Lukkes JL, Fitz SD, Caliman IF, Abreu ARR et al (2020) Panic results in unique molecular and network changes in the amygdala that facilitate fear responses. Mol Psychiatry 25:442-460. https://doi.org/10.1038/s41380-018-0119-0

24. Kohler M, Hirschberg B, Bond CT, Kinzie JM, Marrion NV, Maylie J et al (1996) Small-conductance, calcium-activated potassium channels from mammalian brain. Science 273:1709-1714. https://doi.org/10.1126/science.273.5282.1709

25. Autuori E, Sedlak P, Xu L, M CR, Tedoldi A, Sah P (2019) rSK1 in Rat Neurons: A Controller of Membrane rSK2? Front Neural Circuits 13:21. https://doi.org/10.3389/fncir.2019.00021

26. Stocker M, Pedarzani $P(2000)$ Differential distribution of three $\mathrm{Ca}(2+)$-activated $\mathrm{K}(+)$ channel subunits, SK1, SK2, and SK3, in the adult rat central nervous system. Mol Cell Neurosci 15:476-493. https://doi.org/10.1006/mcne.2000.0842

27. Sailer CA, Kaufmann WA, Marksteiner J, Knaus HG (2004) Comparative immunohistochemical distribution of three small-conductance Ca2+-activated potassium channel subunits, SK1, SK2, and SK3 in mouse brain. Mol Cell Neurosci 26:458-469. https://doi.org/10.1016/j.mcn.2004.03.002

28. Atchley D, Hankosky ER, Gasparotto K, Rosenkranz JA (2012) Pharmacological enhancement of calcium-activated potassium channel function reduces the effects of repeated stress on fear memory. Behav Brain Res 232:37-43. https://doi.org/10.1016/j.bbr.2012.03.037

29. Vick KAt, Guidi M, Stackman RW Jr (2010) In vivo pharmacological manipulation of small conductance $\mathrm{Ca}(2+)$-activated $\mathrm{K}(+)$ channels influences motor behavior, object memory and fear conditioning. Neuropharmacology 58:650-659. https://doi.org/10.1016/j.neuropharm.2009.11.008

30. Criado-Marrero M, Santini E, Porter JT (2014) Modulating fear extinction memory by manipulating SK potassium channels in the infralimbic cortex. Front Behav Neurosci 8:96. https://doi.org/10.3389/fnbeh.2014.00096

31. Lin MT, Lujan R, Watanabe M, Frerking M, Maylie J, Adelman JP (2010) Coupled activity-dependent trafficking of synaptic SK2 channels and AMPA receptors. J Neurosci 30:11726-11734. https://doi.org/10.1523/JNEUROSCI.1411-10.2010

32. Lin MT, Lujan R, Watanabe M, Adelman JP, Maylie J (2008) SK2 channel plasticity contributes to LTP at Schaffer collateral-CA1 synapses. Nat Neurosci 11:170-177. https://doi.org/10.1038/nn2041 
33. Hammond RS, Bond CT, Strassmaier T, Ngo-Anh TJ, Adelman JP, Maylie J et al (2006) Smallconductance Ca2+-activated K+ channel type 2 (SK2) modulates hippocampal learning, memory, and synaptic plasticity. J Neurosci 26:1844-1853. https://doi.org/10.1523/JNEUROSCI.4106-05.2006

34. Disterhoft JF, Oh MM (2006) Learning, aging and intrinsic neuronal plasticity. Trends Neurosci 29:587-599. https://doi.org/10.1016/j.tins.2006.08.005

35. Bond CT, Herson PS, Strassmaier T, Hammond R, Stackman R, Maylie J et al (2004) Small conductance $\mathrm{Ca}$-+-activated $\mathrm{K}+$ channel knock-out mice reveal the identity of calcium-dependent afterhyperpolarization currents. J Neurosci 24:5301-5306.

https://doi.org/10.1523/JNEUROSCI.0182-04.2004

36. Ren Y, Barnwell LF, Alexander JC, Lubin FD, Adelman JP, Pfaffinger PJ et al (2006) Regulation of surface localization of the small conductance Ca2+-activated potassium channel, Sk2, through direct phosphorylation by cAMP-dependent protein kinase. J Biol Chem 281:11769-11779. https://doi.org/10.1074/jbc.M513125200

37. Sun J, Liu Y, Zhu G, Cato C, Hao X, Qian L et al (2020) PKA and Ube3a regulate SK2 channel trafficking to promote synaptic plasticity in hippocampus: Implications for Angelman Syndrome. Sci Rep 10:9824. https://doi.org/10.1038/s41598-020-66790-4

38. Kim G, Lujan R, Schwenk J, Kelley MH, Aguado C, Watanabe M et al (2016) Membrane palmitoylated protein 2 is a synaptic scaffold protein required for synaptic SK2-containing channel function. Elife 5. https://doi.org/10.7554/eLife.12637

39. Zhang G, Asgeirsdottir HN, Cohen SJ, Munchow AH, Barrera MP, Stackman RW Jr (2013) Stimulation of serotonin $2 A$ receptors facilitates consolidation and extinction of fear memory in C57BL/6J mice. Neuropharmacology 64:403-413. https://doi.org/10.1016/j.neuropharm.2012.06.007

40. Spinelli KJ, Taylor JK, Osterberg VR, Churchill MJ, Pollock E, Moore C et al (2014) Presynaptic alphasynuclein aggregation in a mouse model of Parkinson's disease. J Neurosci. https://doi.org/10.1523/JNEUROSCI.2581-13.2014. .34:2037-2050

41. Song Y, Zhu JS, Hua R, Du L, Huang ST, Stackman RW Jr et al (2018) Small-Conductance Ca(2+)Activated $\mathrm{K}(+)$ Channel 2 in the Dorsal Horn of Spinal Cord Participates in Visceral Hypersensitivity in Rats. Front Pharmacol 9:840. https://doi.org/10.3389/fphar.2018.00840

42. Rademacher N, Schmerl B, Lardong JA, Wahl MC, Shoichet SA (2016) MPP2 is a postsynaptic MAGUK scaffold protein that links SynCAM1 cell adhesion molecules to core components of the postsynaptic density. Sci Rep 6:35283. https://doi.org/10.1038/srep35283

43. Heimer L, Van Hoesen GW (2006) The limbic lobe and its output channels: implications for emotional functions and adaptive behavior. Neurosci Biobehav Rev 30:126-147. https://doi.org/10.1016/j.neubiorev.2005.06.006

44. Etkin A, Wager TD (2007) Functional neuroimaging of anxiety: a meta-analysis of emotional processing in PTSD, social anxiety disorder, and specific phobia. Am J Psychiatry 164:1476-1488. https://doi.org/10.1176/appi.ajp.2007.07030504 
45. Francati V, Vermetten E, Bremner JD (2007) Functional neuroimaging studies in posttraumatic stress disorder: review of current methods and findings. Depress Anxiety 24:202-218. https://doi.org/10.1002/da.20208

46. Davis M (1997) Neurobiology of fear responses: the role of the amygdala. J Neuropsychiatry Clin Neurosci 9:382-402. https://doi.org/10.1176/jnp.9.3.382

47. Sengupta A, Yau JOY, Jean-Richard-Dit-Bressel P, Liu Y, Millan EZ, Power JM et al (2018) Basolateral Amygdala Neurons Maintain Aversive Emotional Salience. J Neurosci 38:3001-3012. https://doi.org/10.1523/JNEUROSCI.2460-17.2017

48. Cho JH, Deisseroth K, Bolshakov VY (2013) Synaptic encoding of fear extinction in mPFC-amygdala circuits. Neuron 80:1491-1507. https://doi.org/10.1016/j.neuron.2013.09.025

49. Faber ES, Delaney AJ, Power JM, Sedlak PL, Crane JW, Sah P (2008) Modulation of SK channel trafficking by beta adrenoceptors enhances excitatory synaptic transmission and plasticity in the amygdala. J Neurosci 28:10803-10813. https://doi.org/10.1523/JNEUROSCI.1796-08.2008

50. Ngo-Anh TJ, Bloodgood BL, Lin M, Sabatini BL, Maylie J, Adelman JP (2005) SK channels and NMDA receptors form a Ca2+-mediated feedback loop in dendritic spines. Nat Neurosci 8:642-649. https://doi.org/10.1038/nn1449

51. Sargin D, Oliver DK, Lambe EK (2016) Chronic social isolation reduces 5-HT neuronal activity via upregulated SK3 calcium-activated potassium channels. Elife 5. https://doi.org/10.7554/eLife.21416

52. Roozendaal B, Quirarte GL, McGaugh JL (2002) Glucocorticoids interact with the basolateral amygdala beta-adrenoceptor--CAMP/CAMP/PKA system in influencing memory consolidation. Eur J Neurosci 15:553-560. https://doi.org/10.1046/j.0953-816x.2001.01876.x

53. Young MB, Thomas SA (2014) M1-muscarinic receptors promote fear memory consolidation via phospholipase C and the M-current. J Neurosci 34:1570-1578.

https://doi.org/10.1523/JNEUROSCI.1040-13.2014

54. Elias GM, Funke L, Stein V, Grant SG, Bredt DS, Nicoll RA (2006) Synapse-specific and developmentally regulated targeting of AMPA receptors by a family of MAGUK scaffolding proteins. Neuron 52:307-320. https://doi.org/10.1016/j.neuron.2006.09.012

55. El-Husseini AE, Schnell E, Chetkovich DM, Nicoll RA, Bredt DS (2000) PSD-95 involvement in maturation of excitatory synapses. Science 290:1364-1368

56. Schnell E, Sizemore M, Karimzadegan S, Chen L, Bredt DS, Nicoll RA (2002) Direct interactions between PSD-95 and stargazin control synaptic AMPA receptor number. Proc Natl Acad Sci U S A 99:13902-13907. https://doi.org/10.1073/pnas.172511199

57. Stein V, House DR, Bredt DS, Nicoll RA (2003) Postsynaptic density-95 mimics and occludes hippocampal long-term potentiation and enhances long-term depression. J Neurosci 23:5503-5506

58. Gao C, Tronson NC, Radulovic J (2013) Modulation of behavior by scaffolding proteins of the postsynaptic density. Neurobiol Learn Mem 105:3-12. https://doi.org/10.1016/j.nIm.2013.04.014

59. Ponting CP, Phillips C, Davies KE, Blake DJ (1997) PDZ domains: targeting signalling molecules to sub-membranous sites. BioEssays 19:469-479. https://doi.org/10.1002/bies.950190606 
60. Kim E, DeMarco SJ, Marfatia SM, Chishti AH, Sheng M, Strehler EE (1998) Plasma membrane Ca2+ ATPase isoform $4 \mathrm{~b}$ binds to membrane-associated guanylate kinase (MAGUK) proteins via their PDZ (PSD-95/Dlg/ZO-1) domains. J Biol Chem 273:1591-1595. https://doi.org/10.1074/jbc.273.3.1591

61. Lin L, Sun W, Kung F, Dell'Acqua ML, Hoffman DA (2011) AKAP79/150 impacts intrinsic excitability of hippocampal neurons through phospho-regulation of A-type K+ channel trafficking. J Neurosci 31:1323-1332. https://doi.org/10.1523/JNEUROSCI.5383-10.2011

62. Xia Y, Shang Y, Zhang R, Zhu J (2017) Structure of the PSD-95/MAP1A complex reveals a unique target recognition mode of the MAGUK GK domain. Biochem J 474:2817-2828. https://doi.org/10.1042/BCJ20170356

\section{Figures}

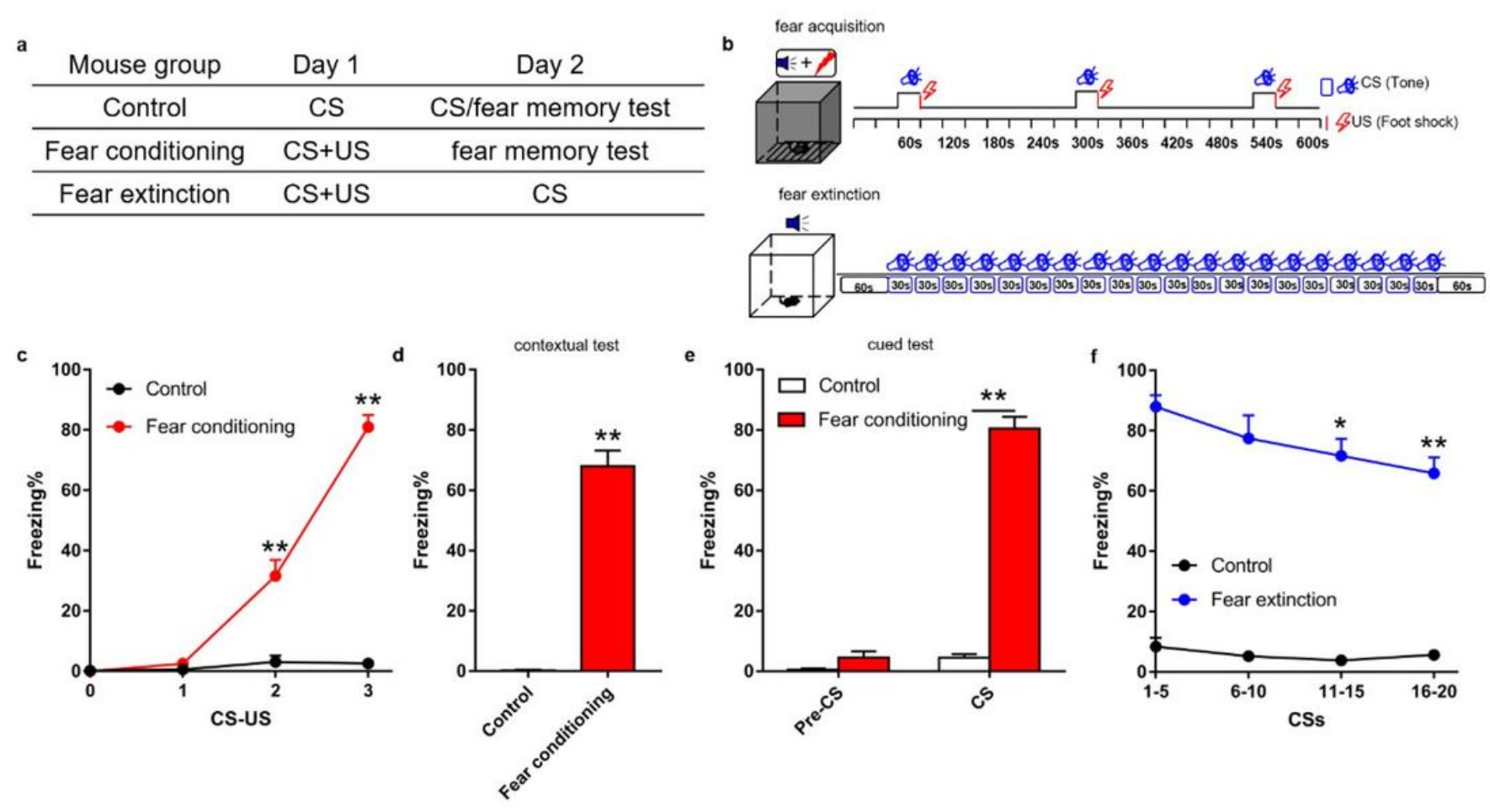

\section{Figure 1}

Fear conditioning and extinction in cue-dependent fear conditioning paradigms in mice. a, b Schematic diagram of the Control, Fear conditioning and extinction groups. $c$ The percentage of freezing in mice during fear acquisition (two-way ANOVA (CS-US times $\times$ group): F3, $56=110.5 ; p<0.01$, main effect of group: $F 1,56=217.7 ; p<0.01 . n=8)$. $d$ The percentage of freezing in mice during the contextual fear memory test (Student's t test, $\mathrm{t} 14=13.15, \mathrm{p}<0.01 . \mathrm{n}=8$ ). e The percentage of freezing in mice during cued fear memory test (two-way ANOVA (CS $\times$ group): F1, $28=315.6 ; p<0.01$, main effect of group: F1, $28=316.5 ; p<0.01 . n=8)$. $f$ The percentage of freezing in mice during fear extinction (two-way ANOVA 
(CSs times $\times$ group): F3, $56=3.223 ; p=0.0293$, main effect of group: F1, $56=529.6 ; p<0.01 . n=8) .{ }^{*} p<$ $0.05, * * p<0.01$.
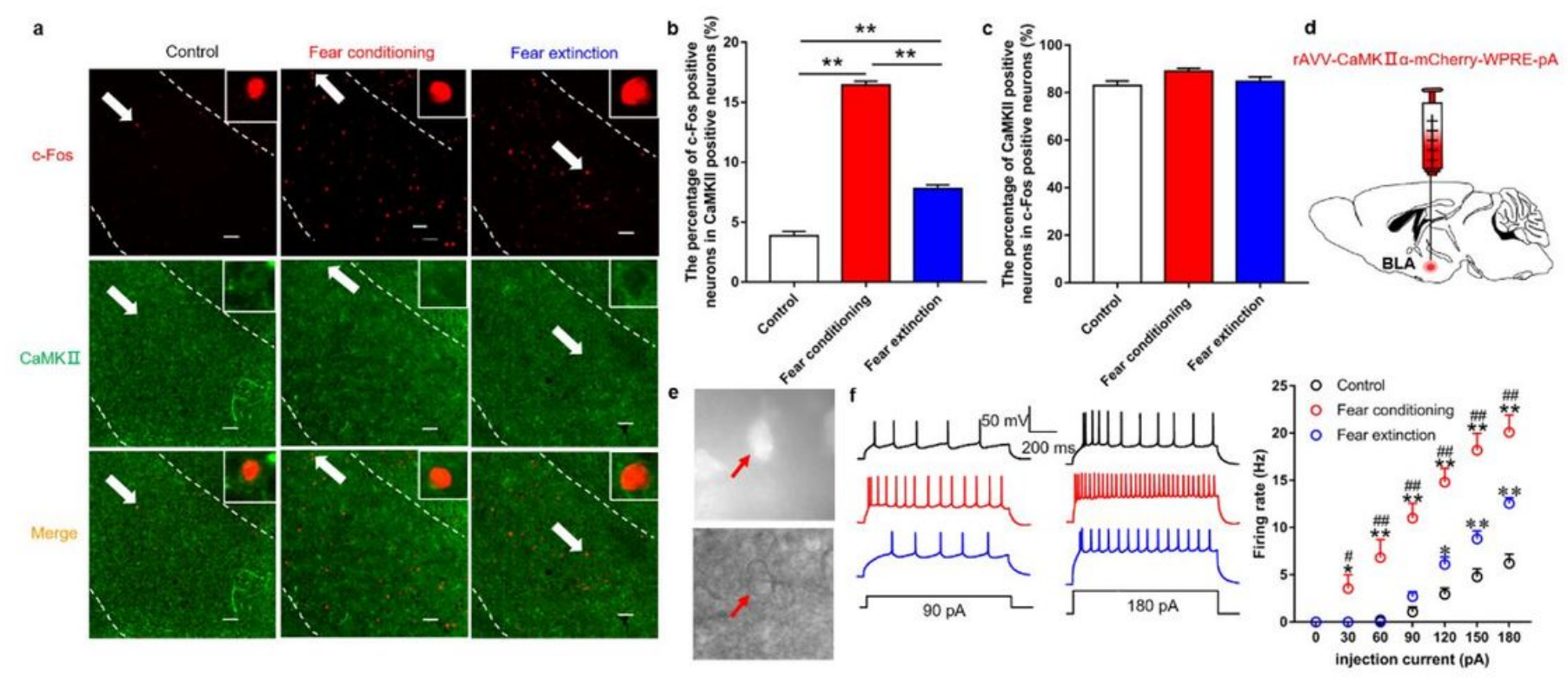

Figure 2

Activation of glutamatergic neurons in the BLA of mice during fear conditioning and extinction. a Representative images showing the expression of c-Fos and CaMKII in the BLA. Scale bar $=100 \mu \mathrm{m}$. b Quantification of the c-Fos+ proportion among CaKII+ neurons (ANOVA, main effect of group: F2,6 = 364.1; $\mathrm{p}$ < 0.01). c Quantification of the CaMKII+ proportion among c-Fos+ neurons (ANOVA, main effect of group: F2, $6=3.275 ; p=0.1093)$. $d$ Schematic showing the injection of rAVV-CaMKIla-mCherry-wpre-pA into the BLA. e The red arrow indicates neurons that express the virus. $f$ The evoked firing rate of glutamatergic neurons in the BLA was increased in a stepwise manner with the stimulus cascade (0-180 pA) (two-way ANOVA (injection current $\times$ group): F6, $294=99.65 ; p<0.01$, main effect of group: F2, $294=$ 158.3; $p<0.01$. ${ }^{*} p<0.05,{ }^{*} p<0.01$ Fear conditioning group VS. Control group, $\# p<0.05, \# \#<<0.01$ Fear conditioning group VS. Fear extinction group, ${ }^{\star} p<0.05,{ }^{\star *} p<0.01$ Fear extinction group VS. Control group. $\mathrm{n}=11-20$ cells, $5-6$ mice $\bullet$ group -1$)$.

\section{Figure 3}

Effects of chemogenetic inhibition of glutamatergic neurons in the BLA on fear memory. a Experimental protocol of chemogenetic manipulation. b Representative images showing the expression of mCherry and CaMKII in BLA neurons. Scale bar $=20 \mu \mathrm{m}$. $\mathrm{c}$ The percentage of freezing in mice during fear acquisition (two-way ANOVA (CS-US times $\times$ group): F3, $40=43.24 ; p<0.01$, main effect of group: F1, $40=0.04439$; $p=0.8342 . n=6)$. $d$ The percentage of freezing in mice during the contextual fear memory test (Student's t test, $\mathrm{t} 10=3.413, \mathrm{p}=0.0066 . \mathrm{n}=6)$. e The percentage of freezing in mice during the cued fear memory test (Two-way ANOVA (CS $\times$ group): F1, $20=42.53 ; p<0.01$, main effect of group: F1, $20=15.24 ; p=$ 
0.0009. $n=6)$. $f$ The percentage of freezing in mice during fear extinction (two-way ANOVA (CSs times $x$ group): F3, $40=8.032 ; p=0.0003$, main effect of group: F1, $40=25.2 ; p<0.01 . n=6) .{ }^{*} p<0.05,{ }^{\star *} p<$ 0.01 .
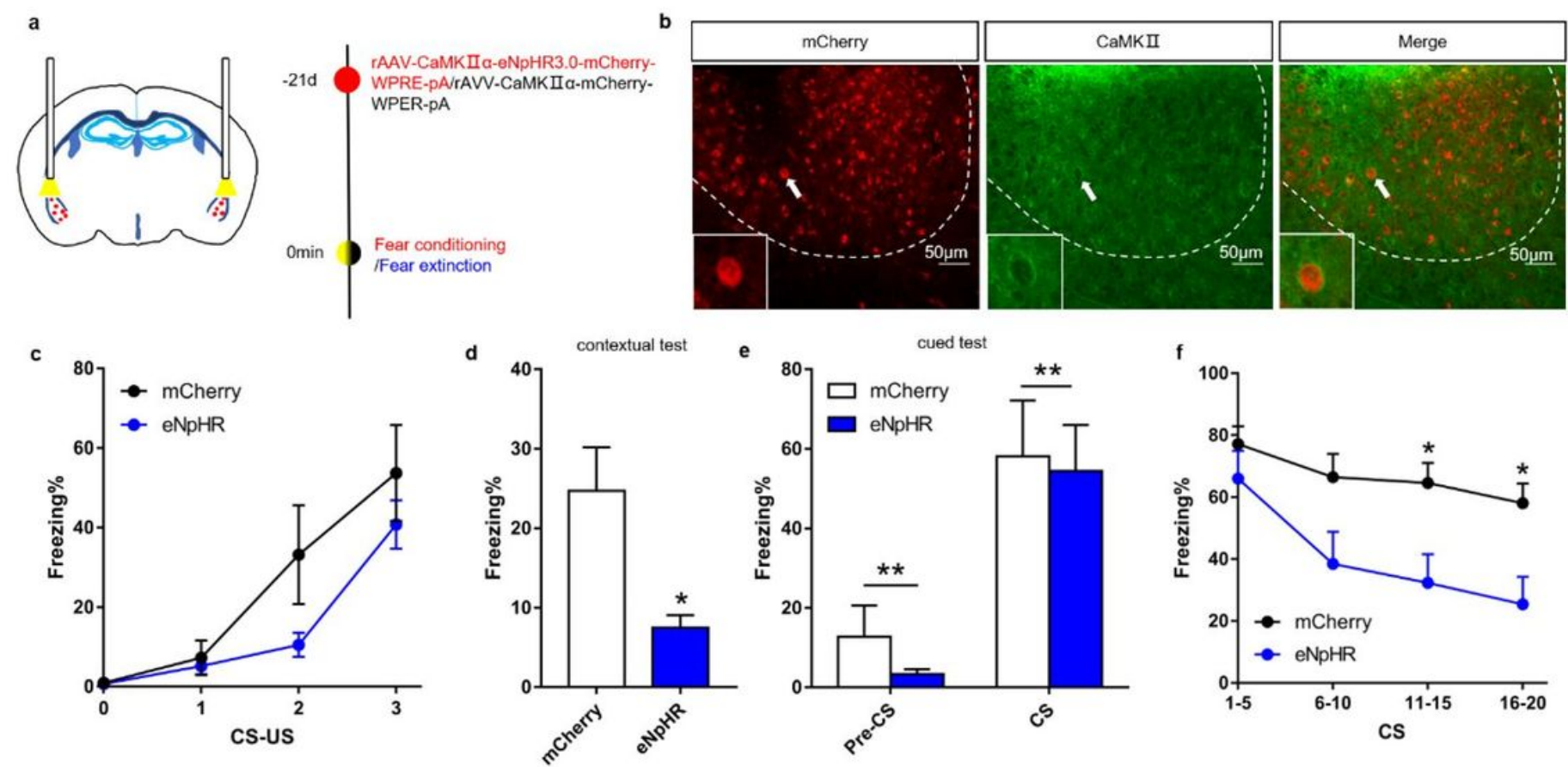

\section{Figure 4}

Effects of optogenetic inhibition of glutamatergic neurons in the BLA on fear memory. a Experimental protocol of optogenetic manipulation. $b$ Representative image showing the coexpression of mCherry in BLA sections stained with a CaMKII antibody. Scale bar $=50 \mu \mathrm{m}$. $\mathrm{c}$ The percentage of freezing of mice in mice during fear acquisition (two-way ANOVA (CS-US times $\times$ group): F3, $40=18.78 ; p<0.01$, main effect of group: $F 1,40=3.909 ; p=0.055 . n=6)$. $d$ The percentage of freezing of mice in mice during the contextual fear memory test (Student's t test, $\mathrm{t} 10=3.031, \mathrm{p}=0.0127 . \mathrm{n}=6$ ). e The percentage of freezing in mice during the cued fear memory test (two-way ANOVA (CS $\times$ group): $F 1,16=58.21 ; p<0.01$, main effect of group: $F 1,16=15.24 ; p=0.3894 . n=5)$. $f$ The percentage of freezing in mice during fear extinction (two-way ANOVA (CSs times $\times$ group): F3, $40=5.006 ; p=0.0048$, main effect of group: $F 1,40=$ 20.68; $p<0.01 . n=6) .{ }^{*} p<0.05,{ }^{* \star} p<0.01$. 

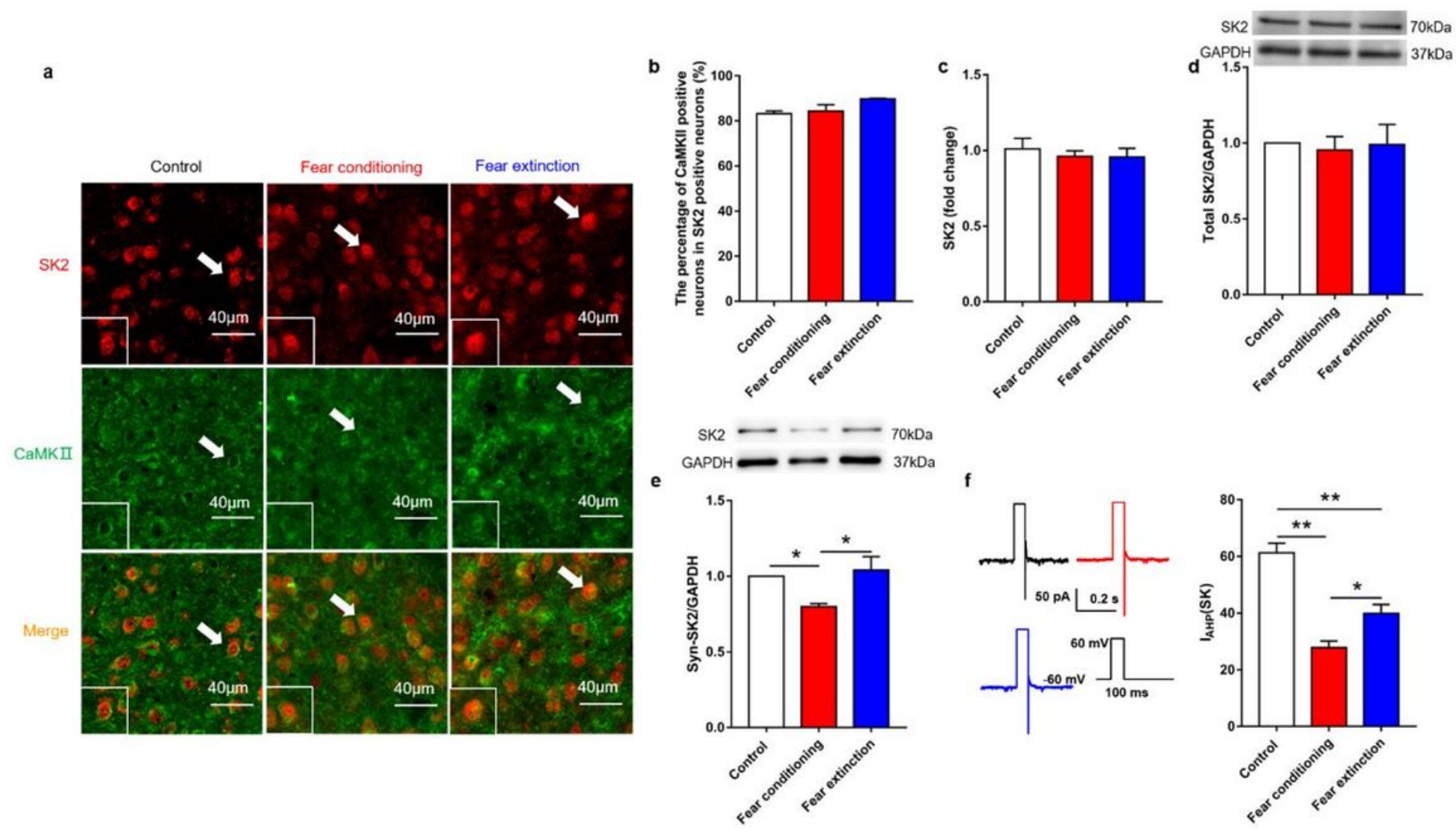

\section{Figure 5}

Changes in SK2 channels in glutamatergic neurons of the BLA during fear conditioning and extinction. a Representative image showing costaining with an SK2 antibody and CaMKII antibody in the BLA. Scale bar $=40 \mu \mathrm{m}$. b Quantification of the CaMKII+ proportion among SK2+ neurons (ANOVA, main effect for group: $F 2,6=3.845 ; p=0.0842 . n=3$ ). $c$ The mRNA expression of the total SK2 channel (ANOVA, main effect of group: $F 2,12=0.2753 ; p=0.7640 . n=4)$. $d$ Western blot analysis of the expression of the total SK2 channel protein in the BLA (ANOVA, main effect of group: $F 2,15=0.06844 ; p=0.9341 . n=6$ ). e Western blot analysis of the expression of synaptic SK2 channel proteins in the BLA (ANOVA, main effect for group: F2,15 $=6.072 ; p=0.0117 . n=6$ ). $f$ The average peak amplitude of IAHP in the Fear conditioning group was reduced compared to that in the other two groups. The average peak amplitude of IAHP in the Fear extinction group was higher than that in the Fear conditioning group but lower than that in the Control group (ANOVA, main effect of group: $F 2,41=31.77 ; p<0.01 . N=5$ ). ${ }^{\star} p<0.05 \square^{\star \star} p<$ 0.01 . 


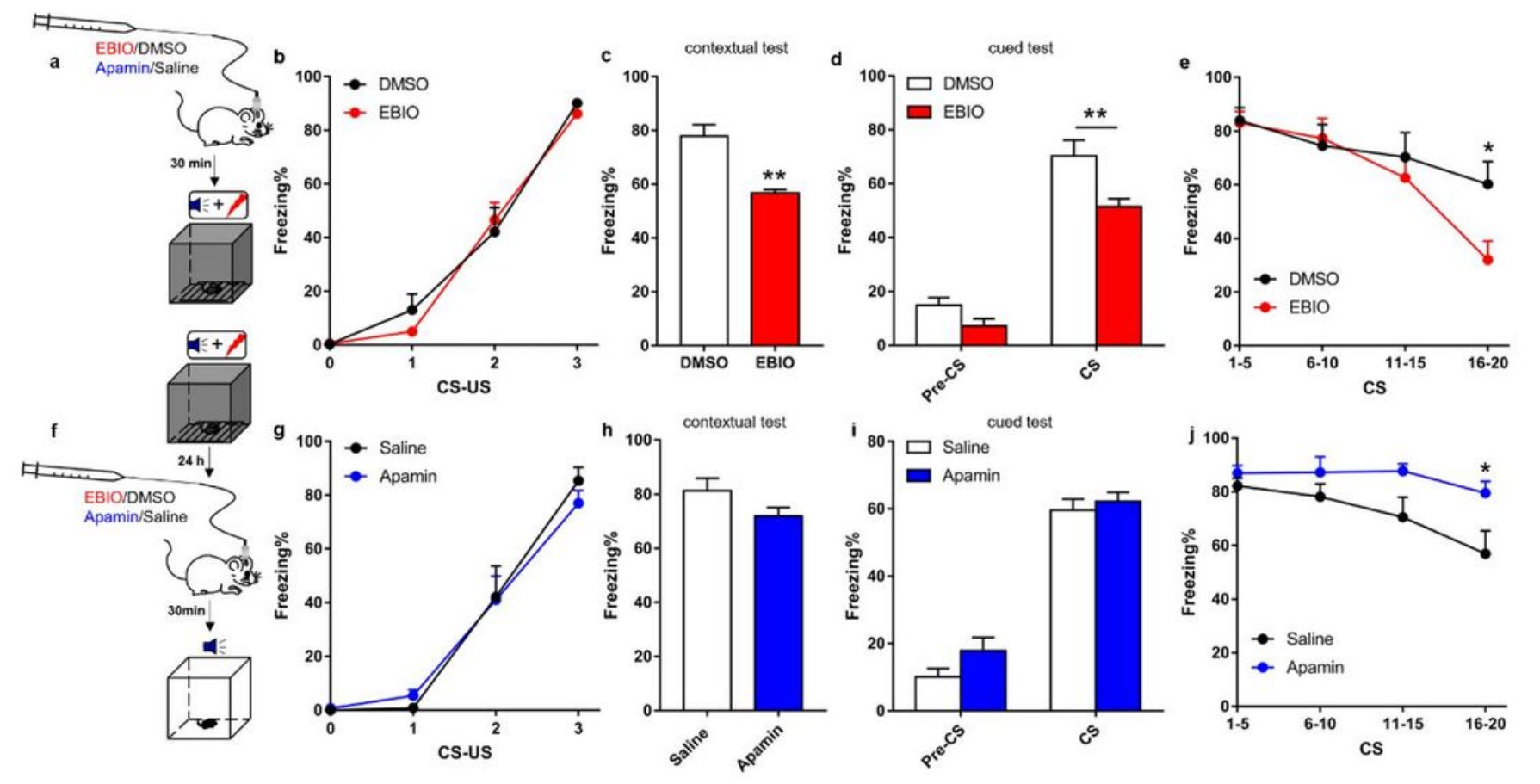

Figure 6

Effects of pharmacological regulation of the SK2 channel in the BLA on fear conditioning and extinction. $a, f$ Experimental protocol for the pharmacological manipulation. $b, g$ The percentage of freezing of mice in the fear acquisition test (two-way ANOVA (CS-US times $\times$ group), b: F3, $56=154.5 ; p<0.01$, main effect of group: F1, $56=0.3283 ; p=0.5689 ; g$ : F3, $56=88.72 ; p<0.01$, main effect of group: $F 1,56=0.06608 ; p$ $=0.7981) . \mathrm{c}, \mathrm{h}$ The percentage of freezing of mice during the contextual fear memory test (Student's $\mathrm{t}$ test, $\mathrm{c}: \mathrm{t} 14=4.731, \mathrm{p}=0.0003 ; \mathrm{h}: \mathrm{t} 14=1.673, \mathrm{p}=0.1165)$. $\mathrm{d}$, $\mathrm{i}$ The percentage of freezing of mice during the cued fear memory test (two-way ANOVA (CS $\times$ group), d: F1, $28=170.5 ; p<0.01$, main effect of group: F1, $28=11.95 ; p=0.0018$; i: F1, $28=217.4 ; p<0.01$, main effect of group: F1, $28=2.692 ; p=$ 0.1120). $e, j$ The percentage of freezing of mice in the fear extinction test (two-way ANOVA (CSs times $x$ group), e: F3, $56=9.765 ; p<0.01$, main effect of group: F1, $56=2.698 ; p=0.1061 ; j: F 3,56=3.734 ; p=$ 0.0162 , main effect of group: $F 1,56=12.6 ; p=0.0008) . n=8,{ }^{\star} p<0.05 \rrbracket^{\star \star} p<0.01$. 


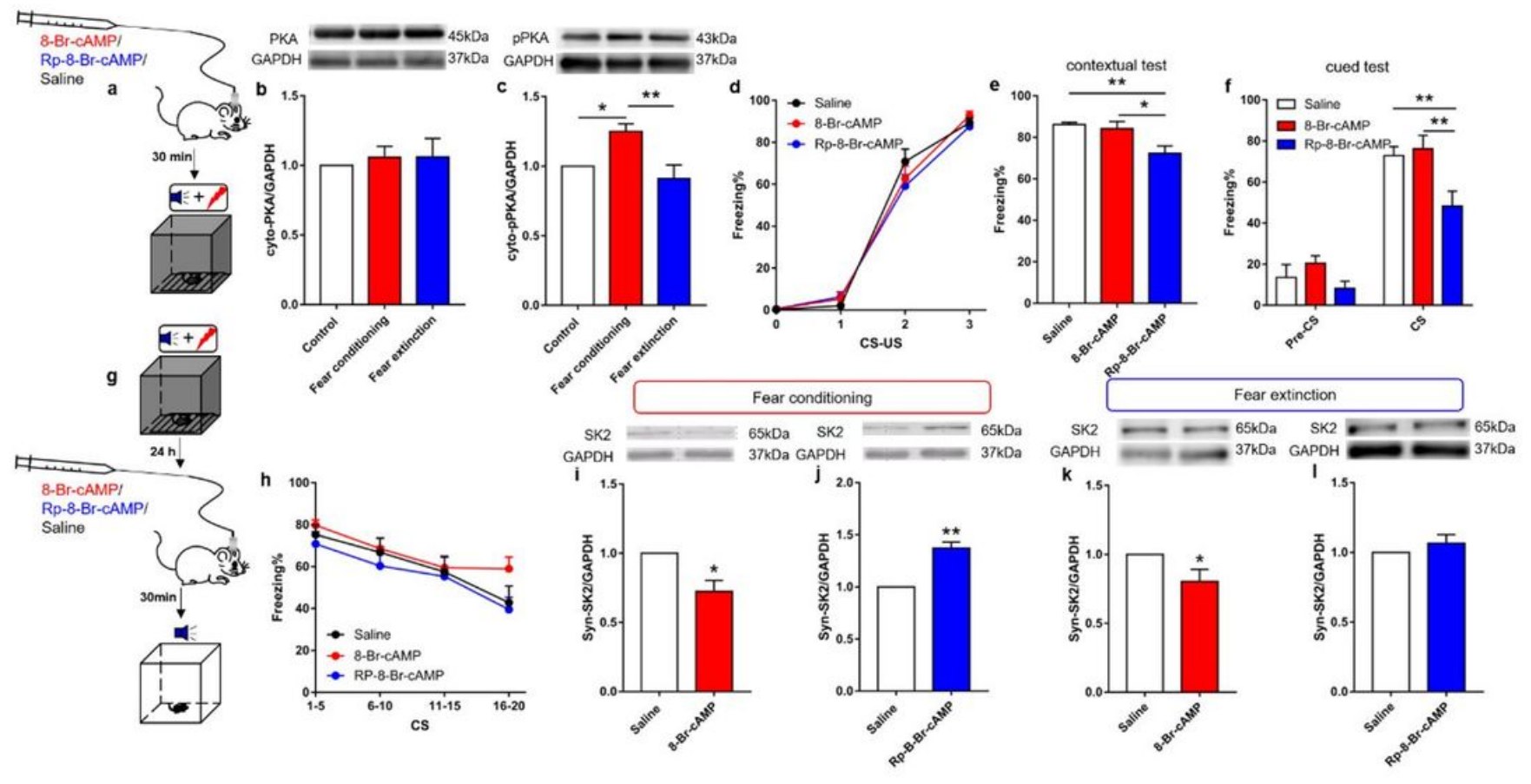

Figure 7

Effects of pharmacological modulation PKA on synaptic SK2 channels to mediate fear conditioning and extinction. a, g Experimental protocol for the PKA manipulation. b Cytoplasmic PKA level in the BLA (ANOVA, main effect of group: F2,15 $=0.1476 ; p=0.8640 . n=6$ ). $c$ Western blot analysis of the expression of cytoplasmic pPKA protein in the BLA (ANOVA, main effect of group: F2,15 = 7.285; $p=$ 0.0062. $n=6$ ). $d$ The fear response of mice in the fear acquisition test (two-way ANOVA (CS-US times $x$ group), F3, $84=523.7, p<0.01$, main effect of group: $F 2,84=0.5087, p=0.6031 . n=8)$. e The percentage of freezing of mice in the contextual fear memory test (ANOVA, main effect of group: F2,21 = 6.38; $p=0.0068 . n=8$ ). $f$ The percentage of freezing of mice during the cued fear memory test (two-way ANOVA (CS $\times$ group), $F 1,42=133.2 ; p<0.01$, main effect of group: $F 2,42=7.263 ; p=0.0020 . n=8) . h$ The fear response of mice in the fear extinction test (two-way ANOVA (CSs times $\times$ group), F3, $84=9.941$; $p<0.01$, main effect of group: $F 2,84=2.449 ; p=0.0925 . n=8)$. $i-I$ Western blot analysis of the expression of synaptic SK2 channels (Student's t test, i: $\mathrm{t} 10=3.47, \mathrm{p}=0.0060$; $\mathrm{j}$ : t10 $=6.541, \mathrm{p}<0.01$; $\mathrm{k}$ : $\mathrm{t} 10=2.258, \mathrm{p}<0.0475 ; \mathrm{l}: \mathrm{t} 10=1.072, \mathrm{p}=0.3088 . \mathrm{n}=6) .{ }^{*} \mathrm{p}<0.05,{ }^{*} \mathrm{p}<0.01$. 


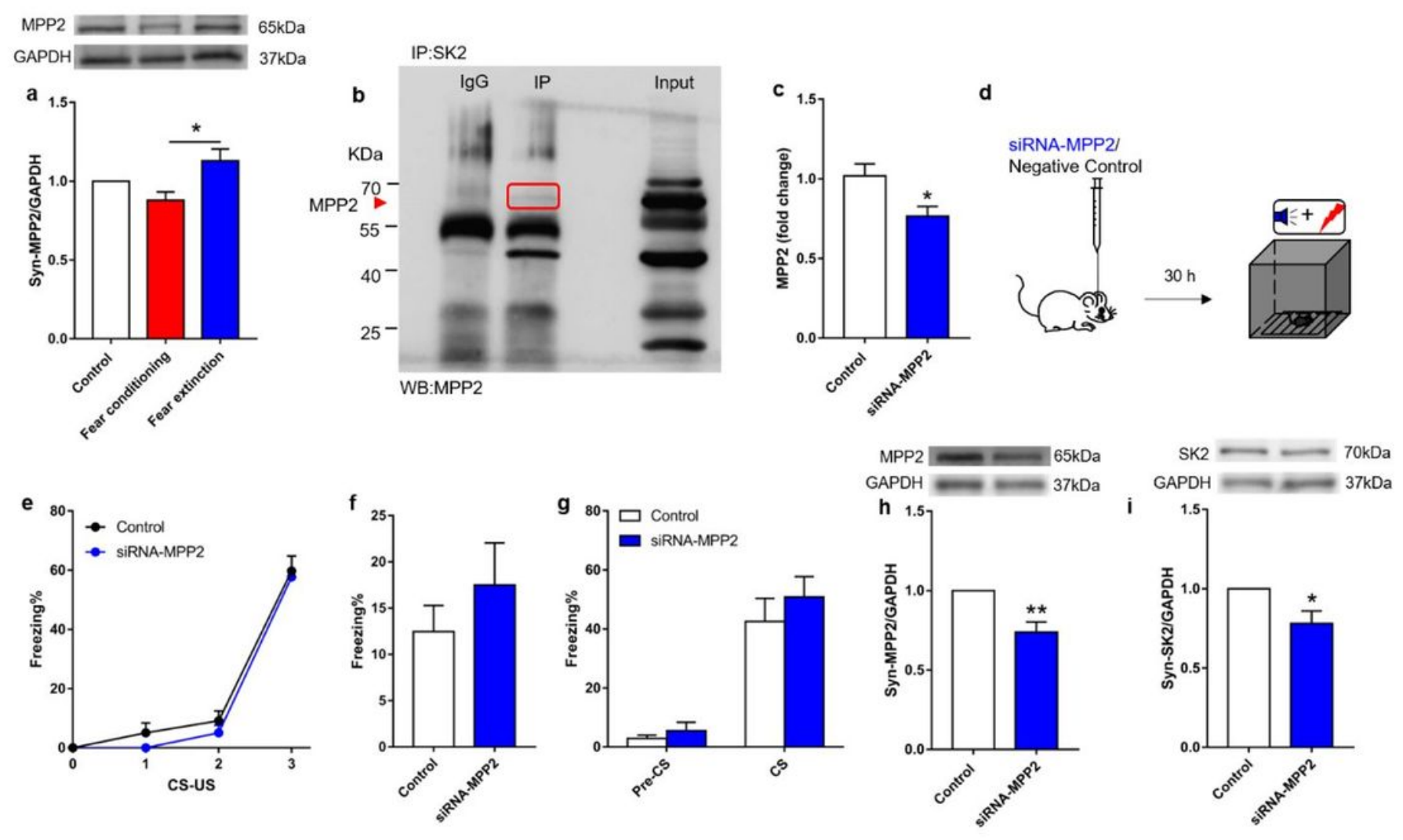

Figure 8

Effects of MPP2 knockdown on synaptic SK2 channels and fear conditioning. a Western blot analysis of the expression of the synaptic MPP2 protein in the BLA (ANOVA, main effect of group: F2,15 = 5.604; $p=$ 0.0152. $n=6$ ). b Coimmunoprecipitations: immunoblots prepared from BLA cell lysates expressing SK2, were immunoprecipitated with an anti-MPP2 antibody or IgG (control). Adjacent blot showing the input of MPP2. $c$ The siRNA targeting MPP2 reduced the expression of the MPP2 mRNA (Student's t test, $t 8=$ 2.607, $p=0.0313 ; n=5)$. $d$ Experimental protocol for downregulating MPP2. e The fear response of mice in the fear acquisition test (two-way ANOVA (CS-US times $\times$ group), F3, $56=119.1$, $p<0.01$, main effect of group: $F 1,56=1.185, p=0.2810 . n=8)$. $f$ The percentage of freezing of mice in the contextual fear memory test (Student's t test, $t 14=0.9419, p=0.3622 ; n=8$ ). $g$ The percentage of freezing of mice during the cued fear memory test (two-way ANOVA (CS $\times$ group), F1, $28=61.37, p<0.01$, main effect of group: F1, $28=1.004, p=0.3250 . n=8)$. $h$ Western blot analysis of the expression of the synaptic MPP2 protein in the mouse BLA (Student's t test, $\mathrm{t} 10=4.058, p=0.0023, n=6$ ). i Western blot analysis of the expression of the synaptic SK2 protein in the mouse BLA (Student's t test, t10 $=2.806, p=0.0186$ ). ${ }^{*}<<$ $0.05,{ }^{\star *} \mathrm{p}<0.01$. 


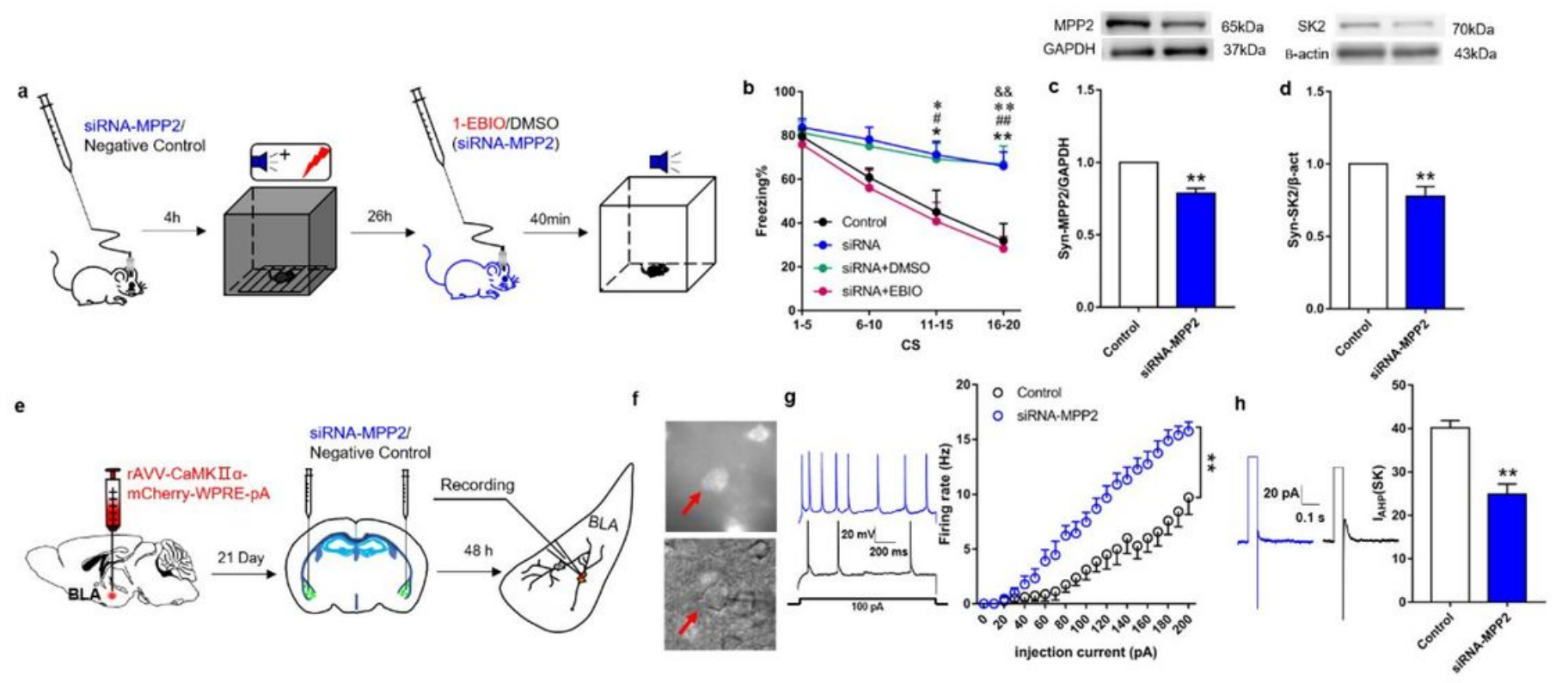

\section{Figure 9}

Effects of MPP2 knockdown on synaptic SK2 channels and fear extinction. a Experimental protocol for downregulating MPP2. $b$ The percentage of freezing of mice during the fear extinction test (two-way ANOVA, ${ }^{*} p<0.05,{ }^{*} p<0.01$ Control group VS. siRNA group, ${ }^{*} p<0.05,{ }^{*} p<0.01$ siRNA group VS. siRNA+EBIO group, $\# p<0.05$, \#\#p < 0.01 siRNA+DMSO group VS. siRNA+EBIO group, \&\&p < 0.01 Control group VS. group, $n=8$ ). c Western blot analysis of the expression of the synaptic MPP2 protein in the mouse BLA (Student t test, $\mathrm{t} 10=6.12, p=0.0001 ; n=6$ ). $d$ Western blot analysis of the expression of the synaptic SK2 protein in the mouse BLA (Student t test, $\mathrm{t} 10=3.338, p=0.0075 ; n=6$ ). e Schematic showing downregulating MPP2 affects BLA glutamatergic neuron. $f$ The red arrow indicates neurons that express the virus. $g$ The evoked firing rate of glutamatergic neurons in the BLA was increased in a stepwise manner with the stimulus cascade (0-200 pA) (two-way ANOVA (injection current $\times$ group): F1, $15=17.83 ; p=0.0007$, main effect of group: F20, $288=7.627 ; p<0.01 . n=8-9$ cells, 5 mice group -1$)$. $h$ The average peak amplitude of IAHP of glutamatergic neurons which was infected by siRNA-MPP2 or negative control in BLA (Student t test, t71 $=5.482, p<0.0001,5$ mice group -1 ). ${ }^{\star} p<0.05,{ }^{*} p<0.01$. 


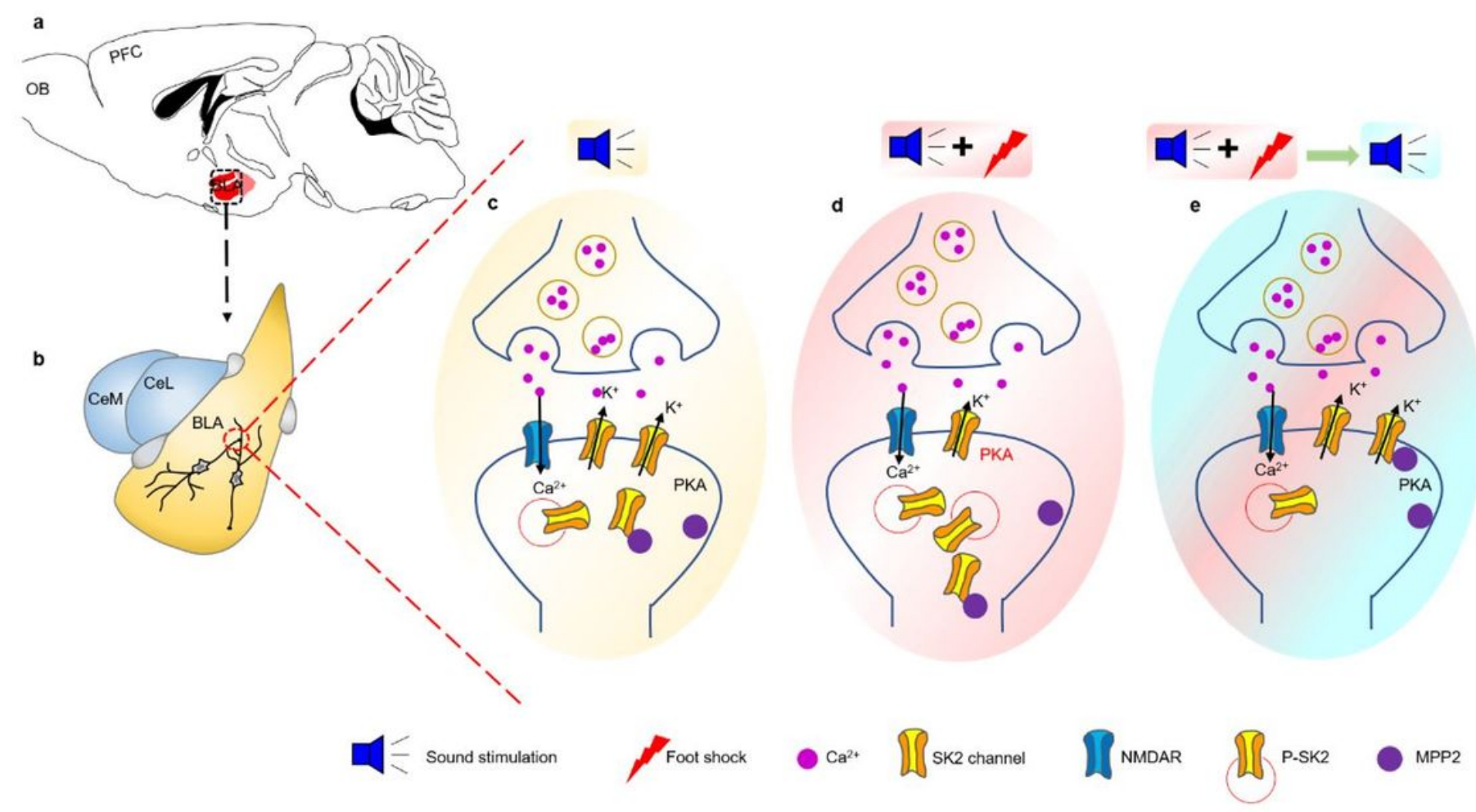

Figure 10

Schematic diagram of the mechanism by which SK2 regulates fear memory. a, b Location and structure of the BLA area. $c$ The distribution of the SK2 channel in the normal state. $d$ In fear conditioning, the expression of synaptic SK2 channels is decreased through phosphorylation mediated by activated PKA. e In fear extinction, the expression of synaptic SK2 channels increases due to the interaction between MPP2 and SK2. 